\title{
Stresses in the metastatic cascade: molecular mechanisms and therapeutic opportunities
}

\author{
Minhong Shen and Yibin Kang \\ Department of Molecular Biology, Princeton University, Princeton, New Jersey 08544, USA
}

\begin{abstract}
Metastasis is the ultimate "survival of the fittest" test for cancer cells, as only a small fraction of disseminated tumor cells can overcome the numerous hurdles they encounter during the transition from the site of origin to a distinctly different distant organ in the face of immune and therapeutic attacks and various other stresses. During cancer progression, tumor cells develop a variety of mechanisms to cope with the stresses they encounter, and acquire the ability to form metastases. Restraining these stress-releasing pathways could serve as potentially effective strategies to prevent or reduce metastasis and improve the survival of cancer patients. Here, we provide an overview of the tumor-intrinsic, microenvironmentand treatment-induced stresses that tumor cells encounter in the metastatic cascade and the molecular pathways they develop to relieve these stresses. We also summarize the preclinical and clinical studies that evaluate the potential therapeutic benefit of targeting these stress-relieving pathways.
\end{abstract}

Metastasis, by which cancer cells spread from primary sites to distant organs, is a highly inefficient process (Gupta and Massagué 2006; Valastyan and Weinberg 2011; Celià-Terrassa and Kang 2016), which requires (1) local invasion and distant extravasation (Aiello and Kang 2019; Lu and Kang 2019), (2) survival of circulating tumor cells (CTCs) (Micalizzi et al. 2017), and (3) colonization and outgrowth in distant organs (Chambers et al. 2002; Massagué and Obenauf 2016). Although conventional treatments such as chemotherapy, radiation and targeted therapy have achieved considerable success (Tolaney et al. 2015; Goncalves et al. 2018), metastatic disease is more resistant to these treatment strategies (Lambert et al. 2017) and is still responsible for a large majority of cancer related deaths (Gupta and Massagué 2006; Seyfried and Huysentruyt 2013). Thus, it is imperative to develop

[Keywords: cancer therapeutics; metastasis; stress;

tumor microenvironment]

Corresponding author: ykang@princeton.edu

Article is online at http://www.genesdev.org/cgi/doi/10.1101/gad.343251.120. therapeutic strategies that can effectively prevent or reduce metastasis.

During cancer metastasis, tumor cells encounter numerous stresses that force them to develop pathways to gain improved fitness in the metastatic cascade. Instead of behaving as traditional driver oncogenes that directly cause cancer, these "metastasis fitness genes" increase the odds of successful metastasis by relieving stresses that are not encountered by normal cells in physiological conditions. Such metastasis fitness genes could serve as novel targets for therapeutic intervention. In this review, we summarize the stresses that tumor cells encounter in the metastatic cascade and the mechanisms they developed to cope with these stresses. We also discuss the potential preventive or therapeutic treatments for metastasis by targeting these metastasis fitness pathways.

\section{Stresses from tumor microenvironment}

Tumor cells are surrounded by stromal cells and a noncellular compartment, which are comprised of a microenvironment that produce stresses to restrain tumor growth and metastasis. In this section, we briefly discuss the common stresses from the tumor microenvironment without distinguishing primary and metastatic sites, as many of such stresses are present in both primary and distant sites. The crosstalk between tumor cells and their microenvironment reshapes the microenvironment to release such stresses and results in increased metastasis fitness, allowing primary tumor cells to gain metastatic abilities and thrive in distant organs (Fig. 1).

\section{Fibroblasts: from metastasis suppression to promotion}

Malignant cells predominantly interact with normal fibroblasts at early stages. In vitro studies revealed that colon cancer cells have reduced proliferation when

(C) 2020 Shen and Kang This article is distributed exclusively by Cold Spring Harbor Laboratory Press for the first six months after the full-issue publication date (see http://genesdev.cshlp.org/site/misc/terms.xhtml). After six months, it is available under a Creative Commons License (Attribution-NonCommercial 4.0 International), as described at http://creativecommons.org/licenses/by-nc/4.0/. 


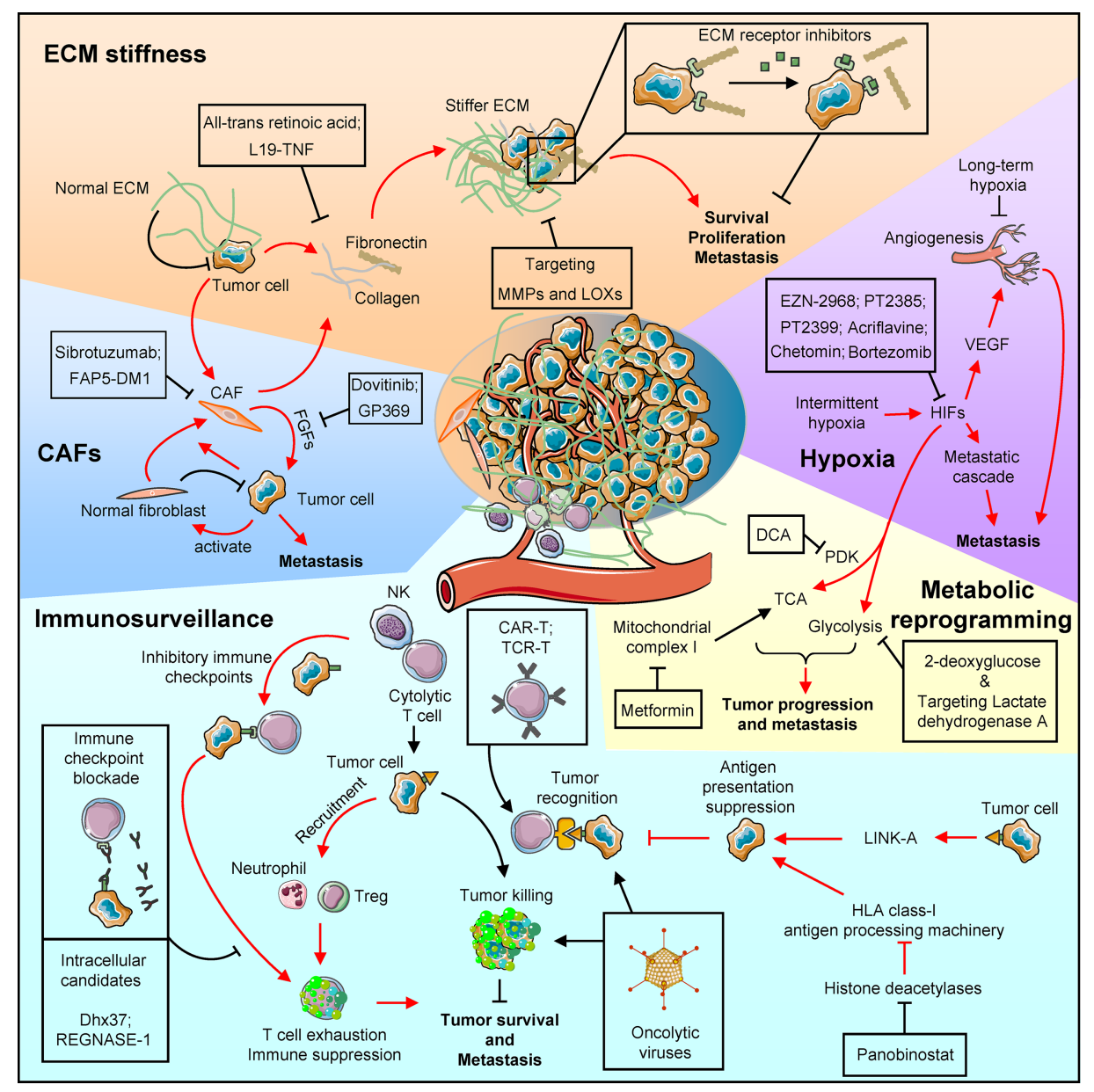

Figure 1. Pathways activated in metastatic cancers to relieve various microenvironmental stresses and therapeutic options to restore such stresses. The clockwise schematic diagrams list various molecular mechanisms and therapeutic strategies. (CAFs) Cancer-associated fibroblasts (CAFs) promote tumor progression and metastasis by secreting supportive factors, such as fibroblast growth factors (FGFs). Monoclonal antibody (Sibrotuzumab) and monoclonal antibody conjugated with cytotoxic drug maytansine (FAP5-DM1) target CAFs, while Dovitinib and monoclonal antibody GP369 inhibit FGF receptor. (ECM stiffness) Both tumor cells and the recruited CAFs increase collagen and fibronectin deposit to make a stiffer extracellular matrix (ECM). All-trans retinoic acid that deactivates CAFs and fibronectin neutralization antibody L19-TNF restore the ECM stress to inhibit metastasis. Other ECM targeting strategies including inhibitors against ECM-modifying enzymes such as lysyl oxidases (LOXs) and matrix metalloproteases (MMPs), or against ECM receptors. (Hypoxia) Hypoxia is commonly observed in solid tumors. Although long-term hypoxia could inhibit metastasis by suppressing angiogenesis, intermittent hypoxia promotes metastasis via hypoxia-inducible factor (HIF)-mediated pathways. Anti-metastasis agents that target HIFs (EZN-2968, Acriflavine, PT2385, and PT2399) or block HIF's transcriptional activity (Chetomin and Bortezomib) are under development. (Metabolic reprogramming) In addition to inducing hypoxia, HIFs also reprogram metabolic pathways by altering the tricarboxylic acid (TCA) cycle and enhancing glycolysis to promote tumor progression and metastasis. Such metabolic adaptation of metastatic cancer can be blocked by dichloroacetate (DCA) and metformin, which target pyruvate dehydrogenase kinase (PDK) and mitochondrial complex I, respectively, to influence TCA. In addition, 2-deoxyglucose treatment and targeting lactate dehydrogenase A reduce endogenous glycolysis. (Immunesurveillance) Tumor cells can be recognized and eliminated by immune cells such as NK and cytolytic T cells. Such immune stress inhibits tumor survival and distant metastasis, but tumor cells often develop multiple pathways to relieve the immune stress. First, tumor cells could modulate the microenvironment to enhance the inhibitory immune checkpoint pathway, and induce T-cell exhaustion. Meanwhile, tumor cells can inhibit immune cell activity by recruiting suppressive cell types, such as neutrophils and regulatory T cells. Tumor cells can also reduce antigen presentation to inhibit the immune recognition. A few therapeutic strategies have been approved by the FDA or are under development to restore immunosurveillance. These strategies include immune checkpoint blockade antibodies and agents that target $\mathrm{T}$-cell intracellular pathways to reduce the exhaustion, engineered $\mathrm{T}$ cells (CAR-T and TCR-T) to enhance the T-cell activity and tumor recognition, oncolytic virus to induce proinformatory environment and enhance T-cell recognition and activity; and elevating tumor antigen presentation by targeting tumor intrinsic pathways, such as Panobinostat that inhibits histone deacetylases to restore human leukocyte antigen (HLA) class I antigen presentation machinery expression. 
cocultured with CCD-18Co and BJ, which are normal colon and skin fibroblasts, respectively (Koh et al. 2019), suggesting that normal fibroblasts restrain tumor progression. Consistently, fibroblasts isolated from disease-free tissues inhibit breast cancer metastasis in vivo (Dumont et al. 2013). However, in advanced stage diseases, cancer-associated fibroblasts (CAFs) facilitate metastasis development (Fig. 1, CAFs). In gastric cancer, the TNFR2-NF-kB-IRF-1 pathway is activated in tumor cells, which in turn promotes the release of TNF-a and increases IL-33 secretion from CAFs. IL-33 signals to its receptor ST2L in tumor cells and induces epithelial-to-mesenchymal transition (EMT) to promote gastric cancer invasion and distant metastasis (Zhou et al. 2020). In an in vitro $3 \mathrm{D}$ coculture system of MDA-MB-231 breast cancer cells, tumor cells activate normal human dermal fibroblasts and human primary mammary fibroblasts, which release matrix metalloproteinases (MMPs) and SDF-1 $\alpha / C X C L 12$ to accelerate aggregation and coalescence of MDA-MB-231 cells (Wessels et al. 2019). Reflecting a phenotypic change from metastasis-suppressive normal fibroblasts to metastasis-promoting CAFs, gene expression profiling showed that normal fibroblasts have high expression of S100A4, TGF- $\beta$, FGF2, PDGFB, and TIMP1, while paired CAFs showed higher levels of FGF7, IL-6, CCL-2, MMP2, MMP9, and MMP11 (González et al. 2016). In metastasis-promoting CAFs, RasGAP and RASAL3 are silenced by promoter hypermethylation at the epigenetic level, allowing the activation of the Ras signaling to promote cancer progression and metastasis (Mishra et al. 2019).

\section{ECM stiffness}

Extracellular matrix (ECM), which is deposited by both malignant and stromal cells, not only provides a physical scaffold for cells, but also initiates signaling events that are required for tissue morphogenesis, differentiation and homeostasis (Frantz et al. 2010). Proteoglycans and fibrous proteins are two major components of ECM /Schaefer and Schaefer 2010). In normal physiological conditions, nonactivated host cells, such as fibroblasts, deposit and organize proteoglycans and fibrous proteins to maintain a tensional homeostasis. Meanwhile, ECM continuously undergoes remodeling to maintain a normal level of stiffness and resist compressive and other stresses in normal tissues (Egeblad et al. 2010). Such remodeling is precisely controlled by MMPs, its counterparts, tissue inhibitors of metalloproteinases, and other enzymes, such as lysyl oxidase (LOX) (Mott and Werb 2004; Lucero and Kagan 2006; Cruz-Munoz and Khokha 2008; Hynes 2009).

Interestingly, such stiffness levels in normal tissues generate stress to suppress proliferative and migratory signaling in cells (Fig. 1, ECM stiffness). For example, breast cancer cells grown in matrix with a stiffness level similar to normal tissue have suppressed Rho/FAK signaling, resulting in inhibited proliferation and migration (Wozniak et al. 2003). In contrast, stiffer ECM is required for EMT and metastasis in hepatocellular carcinoma (Dong et al. $2019 b)$. However, tissue stiffness varies greatly in the human body, ranging from very soft tissues such as brain or breast (Miller et al. 2000; Griesenauer et al. 2017) to rigid tissues, such as bone (Zysset et al. 1999). In the context of metastasis, tumor cells that travel across different organs are challenged by these distinct stiffness conditions. To release such stress, ECM stiffness is altered by tumor cells to facilitate metastasis (Paszek et al. 2005; Levental et al. 2009). For example, breast tumor tissues are twenty times stiffer than normal mammary gland due to increased deposition of ECM from tumors and CAFs (Walker et al. 2018).

Moreover, not only the tumor mass, but also the surrounding stroma and vasculature exhibit increased stiffness (Lopez et al. 2011). Such increased ECM stiffness induces miR-18a expression in breast cancer cells, which in turn reduces expression of the tumor suppressor phosphatase and tensin homolog (PTEN) and promotes breast cancer progression and metastasis (Mouw et al. 2014). Stiff tissue also promotes EMT through the TWIST1-G3BP2 mechanotransduction pathway to enhance metastasis (Wei et al. 2015). In addition to the TWIST-G3BP2 signal axis, the Hippo pathway is also involved in mechanotransduction (Meng et al. 2016). Specifically, YAP/TAZ, which are the core Hippo pathway downstream components, are highly activated in a stiff ECM (Dupont et al. 2011), which in turn promote metastasis (Lamar et al. 2012; Lau et al. 2014). Additionally, stiff ECM-mediated mechanical compression induces miR-9 promoter methylation in breast cancer; and such epigenetic regulation silences miR-9 and elevates the expression of its inhibitory target vascular endothelial growth factor (VEGF)-A to promote metastasis (Kim et al. 2017).

Although a stiffer microenvironment is essential for cancer metastasis and is correlated with poor clinical outcomes (Seewaldt 2014), the stiffness of the tumor cell itself is inversely correlated with its migration and invasion capability (Swaminathan et al. 2011). Cancer cells decrease myosin II expression to decrease stiffness and gain higher migration/invasion potential (Swaminathan et al. 2011). In summary, tumors build a stiffer ECM microenvironment and attenuate self-stiffness to facilitate metastasis.

\section{Hypoxia}

Oxygen is required for energy production and oxygen depletion creates tremendous stress in living cells. An effective oxygen delivery system is developed by the 8th week of gestation in humans to guarantee a precise developmental process (Semenza 2014). In normal physiological conditions, tissues experience various levels of oxygen pressure, ranging from 26 to $51.6 \mathrm{mmHg}$ (McKeown 2014). Such diverse oxygen levels are precisely controlled to maintain oxygen homeostasis in each organ and ensure its function (Carreau et al. 2011; McKeown 2014). However, the disruption of oxygen homeostasis is commonly observed in pathological conditions, such as cardiovascular disease and cancer. In low oxygen conditions (hypoxia), the cells develop various coping strategies, such as arresting cell proliferation, reducing energy consumption, and migration. 
Hypoxia has been recognized as one of the hallmarks of cancer (Hanahan and Weinberg 2011). A majority of solid tumors contain hypoxic regions due to the abnormality of vasculature and high oxygen demands. Hypoxia induces the activation of a variety of signaling pathways. The hypoxia-inducible factors (HIFs) are master regulators of oxygen homeostasis (Ke and Costa 2006). HIF-1a is ubiquitously expressed in all mammalian cells, but the protein is unstable in normoxic conditions through the proline hydroxylation-mediated ubiquitination of HIF-1a by von-Hippel Lindau (VHL) ubiquitin ligase and the subsequent proteasomal degradation (Groulx and Lee 2002; Strowitzki et al. 2019), and becomes stabilized during hypoxia to trigger downstream responses (Semenza 2012). In addition, MAPK/ERK and NF- $\kappa B$ activations have also been reported to be associated with hypoxia (Muz et al. 2015). Previous studies indicated that longterm exposure of lung tumor bearing animals to hypoxia significantly reduces tumor progression and metastasis (Yu and Hales 2011). Although HIFs, such as HIF-1a and HIF-2 $\alpha$ were induced in this context, decreased microvessel density and lower ATP production account for the suppression of lung cancer progression and metastasis (Yu and Hales 2011). The study suggests that longterm and persistent hypoxia restrains metastasis (Fig. 1, hypoxia).

On the other hand, intermittent hypoxia exacerbates melanoma and lung cancer metastasis (Li et al. 2018; Kang et al. 2020). Intermittent hypoxia induced high expression of HIF-1 $\alpha$, metastasis-related MMP as well as VEGF to promote metastasis (Kang et al. 2020). Moreover, increased nuclear translocation of $\beta$-catenin and activated WNT/ $\beta$-catenin signaling under hypoxia promotes the proliferative and migratory properties of tumors (Kang et al. 2020). Consistently, hypoxia is associated with metastasis and poor patient outcomes in the clinic (Luan et al. 2013). Indeed, accumulating evidence revealed that hypoxia is a key factor that supports metastasis (Rankin et al. 2016).

Hypoxia contributes to metastasis by influencing multiple steps of the metastatic cascade, such as invasion, extravasation, colonization, and outgrowth in distant organs. EMT is essential for cancer metastasis ( $\mathrm{Lu}$ and Kang 2019|. Previous studies indicated that HIFs, which are induced by hypoxia, promote invasion and extravasation by directly regulating the EMT transcription factors: Twist (Yang et al. 2008), ZEB1 (Zhang et al. 2015), and Snail (Luo et al. 2011). In addition, HIFs induce expression of VEGF, which stimulates angiogenesis and promotes metastasis (Joyce and Pollard 2009; Tamura et al. 2020). In addition to directly reshaping tumor cells, hypoxia also induces epigenetic reprogramming of normal stromal fibroblasts to result in a CAF-like transcriptome in the cells, which in turn supports cancer progression and metastasis (Becker et al. 2020).

\section{Metabolic reprogramming}

Metabolic reprogramming is another well documented feature of cancer. The metabolic activities of tumor cells are profoundly altered, which could either restrain or accelerate metastasis (Fig. 1, metabolic reprogramming).

Hypoxia induces reactive oxygen species (ROS), which significantly alters metabolic activities in tumor cells. Some metabolic enzymes are directly regulated by ROS levels in cancer (Bhardwaj and He 2020). Moreover, many glycolytic proteins, such as glucose transporters 1 and 3, are transcriptionally activated by HIF-1 under hypoxia, and enhance glycolysis and pentose phosphate pathways in cancer (Ghanbari Movahed et al. 2019). The expression of pyruvate dehydrogenase kinase (PDK) is also activated by HIF-1, which suppresses the activity of pyruvate dehydrogenase and consequently alters the tricarboxylic acid (TCA) cycle in tumor cells (Lu et al. 2008). All these changes result in increased glucose and glutamine metabolism and lactate production during cancer progression and metastasis.

Metabolic reprogramming promotes distant dissemination of tumor cells. In lung cancer, activated EGFR phosphorylates UDP-glucose 6-dehydrogenase (UGDH), which is a key enzyme in the uronic acid pathway that converts UDP-glucose to UDP-glucuronic acid. Phosphorylated UGDH protects the HuR-mediated Snail mRNA stability and thus promotes EMT to enhance metastasis (Wang et al. 2019c). Similarly, in breast cancer, patients with higher asparagine synthetase expression are more vulnerable to metastatic relapse (Knott et al. 2018). Asparagine synthetase is a key metabolic enzyme that converts aspartate and glutamine to asparagine and glutamate (Lomelino et al. 2017). Given the fact that EMT-related proteins have higher ratios of asparagine, asparagine synthetase depletion significantly attenuates breast cancer metastasis by suppressing EMT (Knott et al. 2018). Moreover, an earlier study indicated that tumor cells overcome metabolic stress and promote metastasis by limiting activation of the nutrient sensor AMP-activated protein kinase and releasing the cell motility effector FAK (Caino et al. 2013). Epigenetic changes in tumors have also been observed to relieve metabolic stress. For instance, tumor suppressor genes PTEN, Liver Kinase B1 (LKB1), and $V H L$ are epigenetically silenced by promoter hypermethylation, leading to the activation of cancer-related metabolism pathways such as $\mathrm{PI}$ K/AKT/mTOR and HIF-1 (Trojan et al. 2000; Soria et al. 2002; Vanharanta et al. 2013). Finally, tumor cells under metabolic stress can also escape from immunosurveillance via decreased surface expression of the major histocompatibility complex (MHC) class I (Marijt et al. 2019; Nunes and Everts 2019).

\section{Immunosurveillance}

Immunosurveillance eliminates pathogens and mutated cells to protect us from diseases, including cancer. Cytotoxic $T$ cells are the main immune population that kills tumor cells and eradicates metastasis. Cytotoxic T-cell infiltration is correlated with good metastasis-free survival in cancers (Zhang et al. 2003; Pagès et al. 2005), suggesting that these cells restrain metastasis. $T$ cells are activated by tumor-specific antigens presented by antigen presenting cells and MHC or human leucocyte antigen 
(HLA) class I-positive malignant cells. The activated T cells then destroy tumor cells through granule exocytosis or death ligand/receptor systems to induce apoptotic death (Fig. 1, immunosurveillance). In a prostate cancer model, activated cytotoxic $T$ cells are associated with high expression of Granzyme B, which restrains tumor progression through the granule exocytosis pathway (Poggio et al. 2019). Similarly, activated cytotoxic T cells express death ligands, such as TNF- $\alpha$ that is recognized by TNF receptors (death receptor) to trigger cell death (Vredevoogd et al. 2020). Natural killer (NK) cells also control metastasis through granule exocytosis or death ligand/receptor systems (López-Soto et al. 2017; Barrow et al. 2018; LorenzoHerrero et al. 2019). Interestingly, as part of the innate immune response, NK cells predominantly eliminate HLA class I-negative (antigen presentation-deficient) tumor cells to control metastasis. Moreover, the NK cell-mediated killing of such tumor cells seems to be more effective if the tumor cells are disseminated through blood circulation instead of the lymphatic system /Garrido and Aptsiauri 2019). This observation is evidenced by the accumulation of HLA class I-positive liver metastatic cells in a colorectal cancer model, in which tumor cells disseminate to the liver via portal vein (Kloor et al. 2010). Collectively, metastatic suppression in different organs is based on HLA class I levels in tumor cells, as T cells and NK cells recognize and kill HLA class I-positive and -negative metastatic cells, respectively (Garrido and Aptsiauri 2019). In addition to T cells and NK cells, other immune components, such as macrophages (Shang et al. 2019), mast cells (Komi and Redegeld 2020), and dendritic cells (Wang et al. 2019b), have also been reported to suppress metastasis.

Although immune stress attenuates metastasis, tumor cells develop alternative pathways to release such stress. For example, cytolytic T-cell exhaustion is commonly observed in cancers (Wherry 2011). To maintain balance between disease prevention and autoimmune defects, costimulatory and inhibitory immune checkpoint proteins are expressed on the immune cell surface to precisely control their activity. Tumor cells take advantage of the checkpoint system to induce T-cell and NK cell exhaustion. The programmed death ligand-1/programmed death-1 (PD-L1/ PD-1) signaling pathway is one of the most well studied inhibitory immune checkpoint pathways. Upon binding PD-1 and PD-L1, T cells become exhausted and undergo apoptotic cell death (Zou et al. 2016). As discussed above, tumors are commonly under hypoxia, and such stress could elevate PD-L1 via HIF-1 $\alpha$ to induce T-cell exhaustion and promote metastasis (Noman et al. 2014). Consistently, higher PD-1 or PD-L1 expression is commonly observed in patients with worse clinical outcomes. In addition, tumor cells may also act through other inhibitory pathways, such CTLA-4 (Seidel et al. 2018), LAG-3 (Andrews et al. 2017), NKG2A (Sun et al. 2017), and Tim-3 (Das et al. 2017) to enhance T-cell and NK cell exhaustion and escape from immunosurveillance.

Besides inducing exhaustion, tumor cells also relieve immune stress through other pathways. Losing antigenicity is one of the common mechanisms tumors use to suppress T-cell-mediated tumor cell elimination. Previous studies found that the expression of the human long noncoding RNA, LINK-A, in breast tumors down-regulates antigen peptide-loading complex via K48-polyubiquitination-mediated degradation to inhibit tumor antigen presentation and promote cancer progression and metastasis (Hu et al. 2019b). Moreover, tumor cells also reduce antigen processing and presentation through epigenetic regulation, such as histone deacetylation, which silences the HLA class I antigen processing machinery, such as LMP2, LMP7, TAP1, and TAP2 (Ritter et al. 2017). Such epigenetic alteration decreases tumor antigen presentation, and as a result, facilitates the escape of the tumor cells from immunosurveillance.

In addition to these cell-autonomous pathways, tumors also reshape the tumor microenvironment to prevent $\mathrm{T}$ cell infiltration and activation. In melanoma, $\mathrm{WNT} / \beta$-catenin signaling in tumors attenuates $\mathrm{C}$ - $\mathrm{C}$ motif chemokine ligand (CCL)-4 production in the microenvironment, inhibiting the recruitment of dendritic cells and then suppressing T-cell accumulation and activation (Spranger et al. 2015). Similarly, tumor cells remodel ECM to interrupt T-cell trafficking and accumulation (Slaney et al. 2014). Moreover, tumors recruit regulatory T cells (Treg) to suppress cytolytic $\mathrm{T}$ cells. For example, Polycomb repressor complex 1 promotes prostate cancer metastasis by enhancing CCL-1 secretion, which recruits Tregs to suppress immunosurveillance (Su et al. 2019) (Fig. 1, immunosurveillance).

In addition to suppressing tumor-killing immune cells, tumor cells also actively recruit tumor-promoting immune components. Neutrophils have been reported to support cancer metastasis. Studies indicated that tumorderived CXCL5 recruits neutrophils (Zhou et al. 2012, 2014a), which creates a premetastatic niche to facilitate metastatic colonization (Wculek and Malanchi 2015; Liang et al. 2018). Moreover, tumor cells secret multiple cytokines, chemokines and other factors, such as colonystimulating factor 1 and CCL-2 to attract and induce the M2 polarization of macrophages (Qian and Pollard 2010; Su et al. 2019). M2 macrophages in turn secrete a variety of anti-inflammatory cytokines such as IL-4, IL-10, and IL-13, as well as expressing abundant arginase-1, mannose receptor, and scavenger receptors to relieve immune stress and promote cancer metastasis (Lin et al. 2019; Su et al. 2019).

In summary, tumor cells at primary and metastatic sites commonly suffer from various stresses in the microenvironment as noted above, and metastatic fitness is enhanced as a by-product of stress-relieving mechanisms. Of note, many residual cancers display a period of dormancy before emerging as clinically significant metastases (Sosa et al. 2014). Specifically, dormancy can be classified as tumor mass dormancy or cellular dormancy (Aguirre-Ghiso 2007). In general, dormant tumor cells may also be challenged by the same stresses from tumor microenvironments as noted above. Tumor cells under tumor mass dormancy are suppressed by angiogenic defects-induced hypoxia and metabolic stresses as well as immunosurveillance (Holmgren et al. 1995; Koebel et al. 2007), and such stresses can be relieved to facilitate metastasis with the 
mechanisms described above. On the other hand, stress from ECM could result in cellular quiescence to induce cellular dormancy through integrin-FAK signaling (Aguirre Ghiso 2002; Shibue and Weinberg 2009), while increased ECM stiffness relieves such stress to reactive dormant cancer cells and promote metastasis (Barkan et al. 2010).

\section{Stresses in circulation}

The detachment of malignant cells from the primary tumor microenvironment to become CTCs in circulation is a critical step for metastasis. Although millions of CTCs are shed into circulation every day, it was estimated that $<0.02 \%$ of them are able to form metastasis in distant organs (Chambers et al. 2002). CTCs are constantly challenged by numerous stresses, such as immune cell killing (as discussed above), anoikis, and fluid shear stress. Overcoming such stresses is indispensable for boosting the metastasis fitness of CTCs.

\section{Anoikis}

Detachment of tumor cells from cellular and noncellular components in primary tumors is essential for the dissemination of tumor cells. However, losing contact with these components also triggers apoptosis, which is termed as anoikis (Paoli et al. 2013). Anoikis is a defensive mechanism to prevent the ability of the detached cells to reside and grow in an incorrect location in normal physiological conditions; however, it also serves as a significant barrier for cancer metastasis. Upon detachment, anoikis is induced by death receptor and mitochondria-mediated apoptotic pathways (Fig. 2). Specifically, death receptors (i.e., Fas or TNFR1) activate caspase-8, leading to the cleavage and activation of caspase-3. Meanwhile, BH3-only proteins (i.e., Bim and Bad) promote the assembly and activation of Bax-Bad complex in mitochondria, and consequently activate caspases to trigger apoptosis (Paoli et al. 2013). However, metastatic tumor cells develop a variety of pathways to resistant anoikis (Simpson et al. 2008). A gain-of-function genomic screen identified tropomyosin receptor kinase $\mathrm{B}(\operatorname{TrkB})$, a neurotrophic tyrosine kinase receptor, as a potent inhibitor of anoikis and promoter of metastasis (Douma et al. 2004). MTDH has been shown to promote anoikis resistance by enhancing autophagy through the protein kinase RNA like ER kinase (PERK)-eIF2 $\alpha-$ ATF4-CHOP signaling axis in hepatocellular carcinoma (Zhu et al. 2020). Moreover, pancreatic cancer cells with hyperactivated STAT3 signaling were found to be more anoikis-resistant and with higher metastatic potential (Fofaria and Srivastava 2015). Additionally, breast cancer cells induce anoikis resistance by losing E-cadherin expression (Derksen et al. 2006). In gastric cancer models, Wnt5a activates tumor RhoA to inhibit anoikis in E-cadherin-depleted cells (Hayakawa et al. 2015). Furthermore, in lung cancer, elevated expression of Aiolos, which is a lymphocyte lineage-restricted transcription factor, remodels chromatin structure and epigenetically silences the anchorage reporter p66(Shc) to block anoikis and promote metastasis ( $\mathrm{Li}$ et al. 2014).

In addition to these cell-autonomous pathways, tumor cells also protect themselves from anoikis by modulating the microenvironment. Zhu et al. (2011) found that tumors regulate ROS status in the microenvironment to trigger PI3K/PKBa and ERK prosurvival pathways to promote anoikis resistance. Moreover, tumor cells also escape from anoikis by recruiting CAFs, which secrete insulin-like growth factor-binding proteins to stabilize anti-apoptotic protein Mcl-1 (Weigel et al. 2014).

\section{Fluid shear stress}

After entering the blood or the lymphatic circulation, the tumor cells suffer from fluid shear stress generated by the

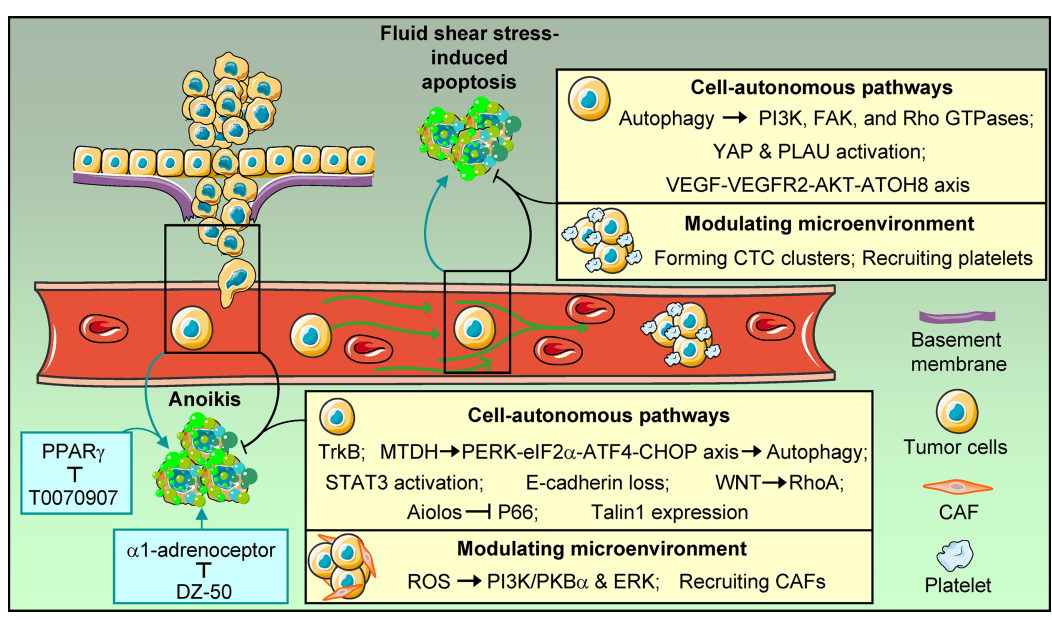
tivation, CAF recruitment, forming CTC clusters and recruiting platelets to relieve anoikis and fluid shear stresses. Inhibitors DZ-50 and T0070907 that target $\alpha 1$-adrenoceptor and peroxisome proliferator-activated receptor $\gamma$ (PPAR $\gamma$ ), respectively, to reduce anoikis resistance have shown anti-metastasis efficacy in preclinical studies.
Figure 2. Stresses upon detachment and in circulation. After detaching from the primary tumor and entering blood circulation, the tumor cells suffer from anoikis and fluid shear stress. Tumor cells relieve such stresses via cell-autonomous pathways and microenvironment modulation. For instance, tumor cells release anoikis stress via Tropomyosin receptor kinase $\mathrm{B}(\mathrm{TrkB})$ activation, MTDH-PERK-eIF2 $\alpha-A T F 4-C H O P$ signaling axis-mediated autophagy, STAT3 activation, E-cadherin loss, WNT-mediated RhoA activation, Aiolos-mediated p66 suppression and elevated Talin1 expression. Similarly, PI3K, FAK, and Rho GTPases; YAP and PLAU; and the VEGFVEGFR2-AKT-ATOH8 axis are activated to enhance circulating tumor cell (CTC) survival in circulation. Tumor cells also use microenvironmental factors, such as reactive oxygen species (ROS)-mediated PI3K/PKBa \& ERK ac- 
flow of liquids (Follain et al. 2020). Given the distinct vascular architecture across the body, the blood/lymphatic flow rates changes constantly, resulting in harsh fluid shear stress to CTCs (Wirtz et al. 2011). Fluid shear stress was found to induce cancer cell death through a BMPRs/ Smad1,5/p38 MAPK signaling-dependent apoptosis pathway (Lien et al. 2013). Moreover, fluid shear stress sensitizes tumor cells to tumor necrosis factor-mediated apoptosis in colon and prostate cancers (Mitchell and King 2013). These findings indicate that fluid shear stress restrains metastasis by reducing CTC survival (Fig. 2).

On the other hand, reducing fluid shear stress promotes cancer invasion and metastasis as cancer cells develop various mechanisms to cope with the stress. The expression of genes that are related to metastasis, such as EMT regulators, are greatly altered in cancer cells under fluid shear stress (Cognart et al. 2020). Wang et al. (2018) found that fluid shear stress induces autophagy in hepatocellular carcinoma cells, which in turn up-regulates PI3K, FAK and Rho GTPases to promote cell migration. Fluid shear stress was also found to activate YAP1 and PLAU signaling to enhance metastasis in prostate (Lee et al. 2017) and breast cancer (Novak et al. 2019), respectively. Fluid shear stress further triggers the VEGF-VEGFR2-AKTATOH8 signal axis to enhance the CTC survival in colon cancer (Huang et al. 2020). In addition to altering cell intrinsic pathways to overcome fluid shear stress and induce metastatic properties, CTCs also protect themselves from the stress by forming clusters (Aceto et al. 2014) or by recruiting platelets in the circulation (Gay and Felding-Habermann 2011). Taken together, although various stresses in the circulation eliminate most of the CTCs and dictate metastasis as a low efficiency process, surviving cells acquire essential traits with enhanced metastasis fitness.

\section{Stresses at colonized organs}

In addition to these common stresses from the tumor microenvironments as noted above, tumor cells also have to cope with organ-specific stresses in order to survive and form new colonies once they reach metastatic organs. Here, we focus on brain, lung, liver, and bone, which are common organ sites affected by metastasis (Obenauf and Massagué 2015; Smith and Kang 2017).

\section{Brain}

The brain, which is separated from the rest of body by the blood-brain barrier, has a unique microenvironment. The blood-brain barrier presents an obstacle to not only tumor cells (Fig. 3A) but also therapeutic drugs, reducing their treatment efficacy for brain metastasis. However, cancer cells remodel the blood-brain barrier and enhance its permeability to bypass the tight junctions (Fares et al. 2020). For example, MMP9 is up-regulated by tumor-derived metalloprotease disintegrin ADAM8, which then promotes transendothelial migration through the bloodbrain barrier (Conrad et al. 2018).

Tumor cells encounter a variety of brain-specific stromal cells, such as astrocytes, microglia and neurons, af- ter the blood-brain barrier transmigration. Among these stromal cells, the contribution of astrocytes to brain metastasis is well characterized. Astrocytes challenge the survival of the infiltrated tumor cells by releasing the proapoptotic cytokine Fas ligand (FasL). However, brain metastatic cells neutralize FasL-mediated killing by expressing serpins that target astrocyte-derived plasminogen activator, which is essential for the release of FasL (Valiente et al. 2014). Moreover, factors that are secreted from brain metastatic cells, such as EGF, TGFa, and macrophage migration inhibitory factor (MIF), activate STAT3 signaling in astrocytes, which in turn promote the survival, proliferation and stemness of tumor cells (Priego et al. 2018). STAT3 activated astrocytes also prevents the immune elimination of brain colonized tumor cells (Priego et al. 2018), further enhancing brain metastasis.

\section{Lung}

As an organ with extensive exposure to the outside environment, the lung creates barriers and stresses to deter colonization by potential pathogens as well as metastatic tumor cells. The tight junctional barrier formed by endothelial cells serves as a structural obstacle for lung extravasation. Moreover, immune populations, such as activated $\mathrm{CD}^{+} \mathrm{T}$ cells, prevent lung colonization through anti-metastatic immunity (Fig. 3B).

However, lung metastases are frequently observed in a variety of cancer types. Tumor cells start to relieve such physical and immune stresses even before they reach the organ. Secreted factors from primary tumors remodel the lung microenvironment to generate premetastatic niches. For example, primary tumor cells under hypoxia produce LOXs, which remodel the lung by increasing the adhesion of myeloid cells to create a premetastatic niche (Erler et al. 2009). Moreover, tumor secreted miR21 and miR-29a bind as ligands to Toll-like receptors to induce prometastatic inflammatory response and promote lung metastasis (Fabbri et al. 2012). Once in the lung, tumor cells secrete miR-105 to silence tight junction protein zona occludens 1 (ZO1) and breach the endothelial barrier to enhance lung colonization (Zhou et al. 2014b). Tumor cells also hijack a4 integrin-expressing macrophages to trigger the initial prosurvival signaling following colonization (Chen et al. 2011). Moreover, by recruiting neutrophils, tumor cells suppress $\mathrm{CD}^{+} \mathrm{T}$-cell activation to restrain anti-metastatic immunity (Wculek and Malanchi 2015).

\section{Liver}

Unlike the brain and lung, the vessels in the liver are fenestrated and lack an organized basement membrane that wraps endothelial cells. In this regard, liver metastatic cells face much less stress from tight junctional barriers during extravasation.

Liver sinusoidal endothelial cells (LSECs) are the first group of stromal cells that metastatic tumors encounter in liver. Upon the interaction with tumor cells, LSECs 


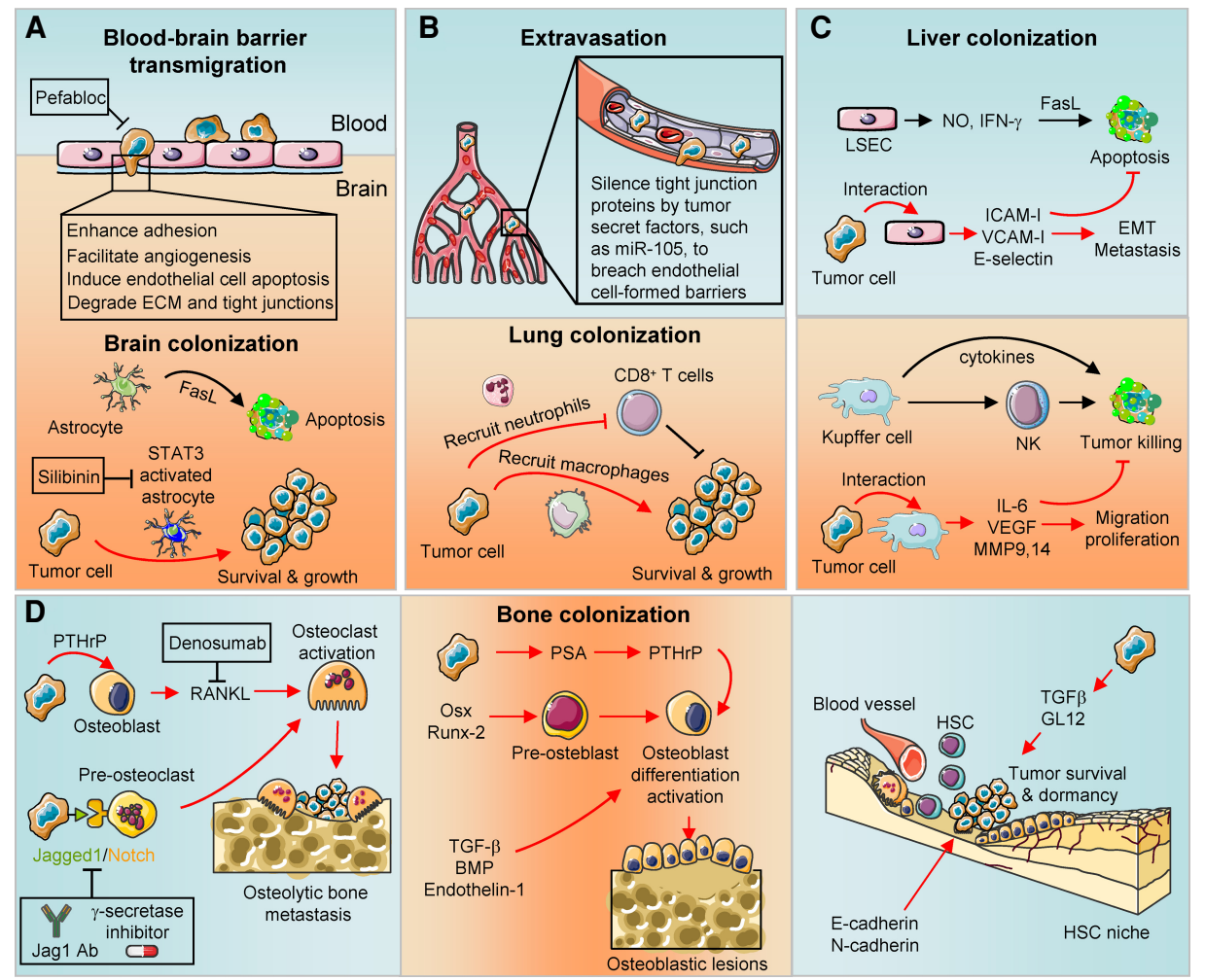

Figure 3. Stresses at specific metastatic organs and relieving pathways. (A) The blood-brain barrier serves as the first line of defense to prevent brain colonization. However, tumor cells transmigrate the barrier by enhancing adhesion, facilitating angiogenesis, inducing endothelial cell apoptosis, and degrading ECM and tight junctions. Upon colonization, while capable of inducing tumor apoptosis at the beginning, astrocytes are activated by tumors via the STAT3 pathway, and instead promote metastatic outgrowth in the brain. Protease inhibitor Pefabloc and STAT3 inhibitor silibinin may reduce brain metastasis by enforcing blood-brain barrier and deactivating astrocytes, respectively. $(B)$ Endothelial cells formed tight junctions to prevent lung colonizing. Immune populations, such as CD8 ${ }^{+} \mathrm{T}$ cells, restrain the tumor survival at the lung. However, tumor cells secrete factors, such as miR-105, to target tight junction proteins and bypass the endothelial barrier. Tumor cells also recruit neutrophils and macrophages to suppress $\mathrm{CD} 8^{+} \mathrm{T}$-cell activation and gain prosurvival signaling after lung colonization. $(C)$ Liver sinusoidal endothelial cells (LSECs) release nitric oxide (NO) and IFN- $\gamma$ to induce tumor cell apoptosis upon interaction. However, tumor cells relieve such apoptotic stress by releasing adhesion molecules, such as ICAM-I, VCAM-I, and E-selectin. During liver colonization, Kupffer cells and NK cells can eliminate tumor cells. However, tumor cells educate Kupffer cells to produce cytokines and growth factors to enhance tumor survival and metastasis. $(D)$ During the development of osteolytic bone metastasis of breast cancer, tumor cells activate osteoclasts through parathyroid hormone-related peptide (PTHrP)-receptor activator of NF-kB ligand (RANKL) or Jagged1/Notch signaling. Tumor cells could also activate osteoblasts via prostate-specific antigen (PSA)PTHrP signaling, Osx, Runx-2, or TGF $\beta$ family members to form osteoblastic lesions. In addition, tumor cells may take advantage of existing niches for normal adult tissue stem cells, such as hematopoietic stem cell (HSC), to gain prosurvival signaling during bone metastasis. Strategies that target RANKL (Denosumab) or block Jagged1/Notch signaling (Jagged1 antibody and $\gamma$-secretase inhibitor) could restore bone microenvironmental stress and reduce bone metastasis.

secrete nitric oxide (NO) and IFN- $\gamma$, which result in the FasL-induced apoptosis to restrain liver colonization (Braet et al. 2007). Moreover, following liver colonization, Kupffer cells, which are bone marrow-derived macrophages, can recognize and eliminate tumor cells (Kimura et al. 2016). Furthermore, Kupffer cells release a variety of cytokines to activate other anti-tumor innate immune populations, such as NK cells (Van den Eynden et al. 2013). Collectively, these liver resident cells work together to prevent liver metastasis (Fig. 3C).

Although LSECs, Kupffer cells, and NK cells serve as the first line of defense to prevent liver metastasis, the stresses they generate also drive the development of metastasis fitness pathways. For example, upon the interaction of tumor cells and LSECs, increased expression of prometastatic surface adhesion molecules, such as VCAM-I, ICAM-I and E-selectin have been observed (Brodt et al. 1997). LSECs also contribute to liver metastasis by facilitating EMT and tumor-induced angiogenesis (Ou et al. 2014; Banerjee et al. 2015). Similarly, adhesion to tumor cells promote the Kupffer cells to produce cytokines and growth factors, such as IL-6, VEGF, MMP9 and MMP14, to enhance tumor survival, proliferation and migration, and thereby promote liver metastasis (Fig. 3C; Brodt 2016). 


\section{Bone}

Bone metastasis is a common occurrence in breast and prostate cancer patients. However, in breast cancer, less than a quarter of the patients with CTCs have detectable disseminated tumor cells in bone (Fortunato et al. 2009), suggesting that there are significant stresses in the bone to prevent the colonization and growth of CTCs. Bone is continuously undergoing remodeling, a process mediated by osteoclasts and osteoblasts; such highly dynamic remodeling presents challenges for tumor cells colonizing the bone (Croucher et al. 2016). Moreover, as the weight bearing skeleton of our body, the bone ECM is usually more rigid than primary sites as mentioned above, which generates additional stress to prevent bone metastasis.

To relieve such stresses, bone metastatic cells hijack osteoclasts and osteoblasts to create favorable niches for bone metastasis (Fig. 3D). For example, in breast cancer, bone metastatic cells express elevated levels of parathyroid hormone-related peptide (PTHrP), which triggers osteoblasts to release receptor activator of NF- $\mathrm{KB}$ ligand (RANKL), and thereby activating osteoclasts to form osteolytic lesions (Macedo et al. 2017). Breast cancer cells were also reported to activate osteoclast differentiation and bone metastasis through Jagged1-Notch signaling (Sethi et al. 2011; Zheng et al. 2017). Instead of activating osteoclasts, prostate cancer cells can produce prostatespecific antigen (PSA) to cleave PTHrP and reduce its activity, possibly shifting prostate cancer bone metastasis to osteoblastic lesions (Iwamura et al. 1996; Macedo et al. 2017). Bone metastatic cells can also take advantage of osteogenic and hematopoietic stem cell niches through adhesion molecules, such as E-selectin and E-cadherin, to gain stemness and proliferative abilities (Shiozawa et al. 2011; Wang et al. 2015; Esposito et al. 2019). Moreover, in the face of increased ECM rigidity in bones, tumor cells have activated GL12 and TGF- $\beta$ signaling, which enhance the development of bone metastasis (Ruppender et al. 2010; Johnson et al. 2011).

In summary, tumor cells that disseminate to distant organs are challenged by distinct organ-specific stresses that limit metastatic colonization. Metastatic cells develop organ-specific pathways to relieve such stresses and enable successful colonization.

\section{Treatment-induced stresses}

In addition to the stresses that are inherently generated during tumor progression and metastasis, cancer therapeutics also create harsh conditions either by directly targeting malignant cells or by remodeling microenvironments.

\section{Nontargeted therapy}

Although surgical removal of tumors could cure the disease in some cancer patients, accumulating evidence suggests that the surgical insult also increases the risk of metastasis (Fig. 4A). Moreover, malignant cells may dis- seminate to distant organs as early as the preneoplastic stage (Rhim et al. 2012; Kang and Pantel 2013) and surgical removal of primary tumors may actually foster the tumor outgrowth at metastatic sites.

Surgical stress could trigger metastasis through multiple mechanisms. First, the damage to patients' tissues could increase the number of tumor cells in circulation (Yamaguchi et al. 2000), significantly elevating the risk of metastasis. Second, tissue damage also alters the microenvironment to promote metastasis. For instance, surgeryinduced wounds or infections create an inflammatory environment, which then up-regulates lipocalin2 expression and results in EMT to promote metastasis (Jung et al. 2017). Moreover, surgery induces the production of ECM proteins, which enhances the attachment and cluster formation of CTCs, and as a result, protects CTCs from anoikis and fluid shear stress (Chen et al. 2019). In addition, surgery could elicit an immunosuppressive state to promote the immune escape of tumor cells (Chen et al. 2019). Surgical removal of primary tumors may also eliminate a major source of circulating angiogenesis inhibitors, allowing outgrowth of metastases (O'Reilly et al. 1994). Last, many anesthetic agents used in surgery have been reported to contribute to tumor metastasis (Tavare et al. 2012).

In addition to surgery, chemotherapies and radiation therapies are commonly used in cancer patients. Chemotherapies and radiation therapies suppress cancer progression and metastasis by inducing DNA damage, RNA and protein synthesis alteration, and cell cycle arrest. Although chemotherapy- and radiation-induced stresses have been proven effective in restraining tumor progression and metastasis, these therapies are usually associated with severe side effects due to the lack of specificity. Furthermore, tumor cells can develop pathways to exacerbate metastasis in response to these treatments (Fig. 4B). For example, breast cancer cells activate astrocytes (Chen et al. 2016) and osteoclasts (Zheng et al. 2017) to enhance chemoresistance and promote brain and bone metastasis, respectively. Moreover, CAFs that are recruited by tumor cells were also reported to promote chemoresistance and metastasis by secreting exosomes (Hu et al. 2019a). Similarly, tumors also release radiation therapy stress with increased metastatic potential through multiple intrinsic and extrinsic pathways, as summarized by Sundahl et al. (2018).

\section{Targeted therapy}

With increasing knowledge about signaling pathways essential for cancer progression and metastasis, drugs that target key components of these pathways have been developed and approved for clinical use (Table 1). For instance, anti-angiogenic therapies, such as anti-VEGF antibody (bevacizumab) and VEGF-R tyrosine kinase inhibitor (sunitinib), which induce angiogenesis stress have been approved for treatment of colorectal and other cancers (Table 1). However, tumor cells develop alternative pathways to relieve such stress, and sometimes, even enhance metastasis (Pàez-Ribes et al. 2009). Colon cancer cells 


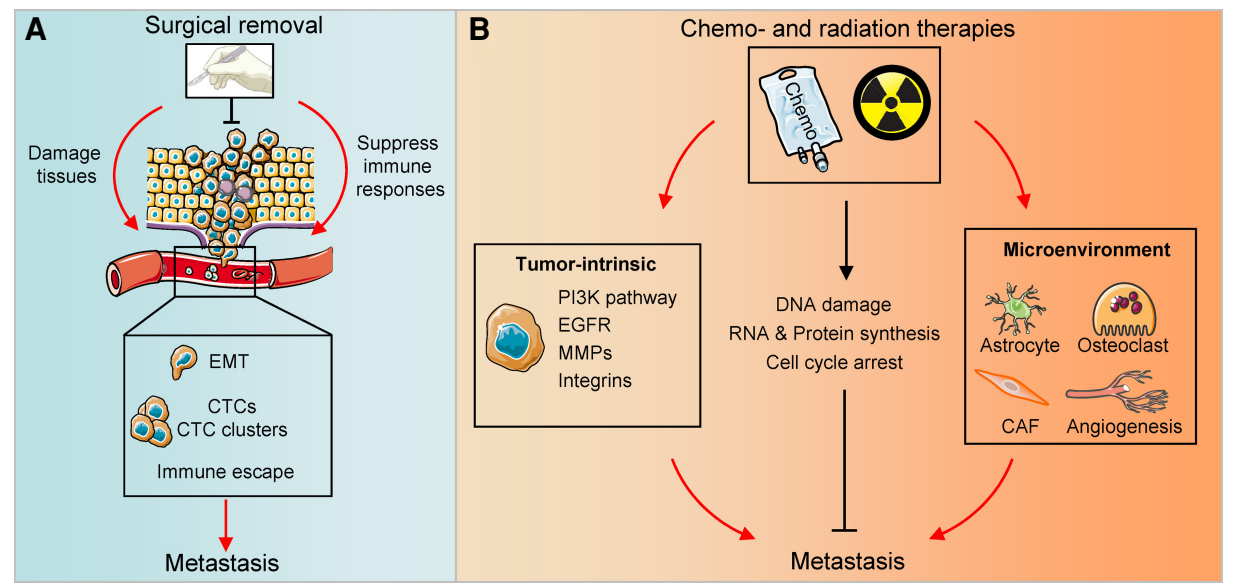

Figure 4. Nontargeted therapy induced stresses. $(A)$ Instead of eliminating tumors, surgical removal could inadvertently enhance metastasis. Surgical process damages tissues to increase CTCs in circulations. Moreover, it alters the microenvironment to promote epithelialmesenchymal transition (EMT) and CTC cluster formation and thereby facilitating metastasis. Surgery also creates an immunosuppressive microenvironment to enhance tumor immune evasion. $(B)$ Chemotherapies and radiation therapies prevent metastasis by inducing DNA damage, RNA \& protein synthesis alteration, and cell cycle arrest. However, these therapies also drive tumor-intrinsic treatment resistant pathways, such as PI3K activation, EGFR hyperactivation, MMPs and integrins elevation. Moreover, chemotherapies and radiation therapies also shape microenvironment, such as activating astrocytes, osteoclasts and CAFs, or promoting angiogenesis to release the stress and thus promote metastasis.

adapt to bevacizumab and sunitinib treatments by elevating the expression of VEGF/VEGF-R family members as well as by activating the neuropilin-1/c-Met pathway, resulting in increased cell migration and invasion (Tomida et al. 2018). In breast cancer, treatment with poly(ADP-ribose) polymerase (PARP) inhibitor Olaparib promotes osteoclast differentiation, immune suppression and bone metastasis (Zuo et al. 2020). Cancer cells have also been found to overcome the proliferative and survival stresses that induced by anti-EGFR or anti-CDK4/6 therapies via activating PI3K-AKT pathway (Fuchs et al. 2008; Jansen et al. 2017), which is correlated with increased metastasis in multiple cancers (Fuchs et al. 2008; Pierobon et al. 2017).

\section{Immunotherapy}

Immunotherapy, especially immune checkpoint blockade therapy, has achieved impressive clinical success in some cancer types (Table 1). Immune checkpoints are crucial to prevent immune cells from attacking healthy cells indiscriminately and maintain immune system homeostasis. However, tumor cells can take advantage of these checkpoint pathways to escape immunosurveillance. Anti-CTLA4 or PD-1/PD-L1 immune checkpoint blockade strategies have been developed to restore immune pressure, leading to reduction or complete eradication of tumors. However, many tumors develop resistant pathways to blunt such curative responses and gain metastatic potential. For example, tumor cells lose PTEN expression to activate the PI3K-AKT pathway, which relieves the immune checkpoint blockade therapy-induced stress (Peng et al. 2016). The activated PI3K-AKT pathway further promotes metastasis as mentioned above (Pierobon et al.
2017). In addition to tumor cell-autonomous resistance, CD38 on T cells is elevated upon PD-1/PD-L1 blockade to allow escape of the tumor from the therapy (Chen et al. 2018). CD38 has been reported to promote metastasis via adenosine-mediated $\mathrm{CD} 8^{+} \mathrm{T}$-cell suppression (Chen et al. 2018). Moreover, tumors under immune checkpoint blockade therapies have been found to up-regulate other inhibitory immune checkpoints in T cells, such as VISTA and TIM-3, to suppress T-cell activation (Koyama et al. 2016; Gao et al. 2017) and promote cancer metastasis (Cao et al. 2013; Liao et al. 2018). Finally, tumor cells could remodel the microenvironment to resist immunotherapy and enhance metastasis. For example, loss of PTEN in tumors up-regulates VEGF, which in turn promotes abnormal angiogenesis and limits $\mathrm{CD} 8^{+}$ T-cell infiltration to induce PD-1/PD-L1 blockade resistance (Peng et al. 2016). VEGF-stimulated angiogenesis further increases the risk of metastasis (Skobe et al. 2001; Stacker et al. 2001).

\section{Anti-metastasis therapeutics targeting stress-relieving pathways}

As tumor cells encounter harsh stresses during metastatic progression or under treatment, stress-relieving mechanisms are developed to bypass these hurdles and increase the risk of metastasis. Targeting the relevant metastasis fitness genes serves as a promising strategy to develop novel therapeutics.

\section{Targeting CAFs}

CAF is the major stromal cell type in the tumor microenvironment and plays an active role in promoting 
Table 1. FDA approved targeted therapies for solid tumors

\begin{tabular}{|c|c|c|c|}
\hline Target & Agents & Applied cancer types & $\begin{array}{l}\text { Stresses induced by the } \\
\text { treatment }\end{array}$ \\
\hline HER2 & $\begin{array}{l}\text { Trastuzumab emtansine, Neratinib, } \\
\text { Pertuzumab, Trastuzumab }\end{array}$ & $\mathrm{HER}^{+}{ }^{+}$breast cancer, HER $2^{+}$gastric cancer & $\begin{array}{l}\text { Reduce proliferation and } \\
\text { survival }\end{array}$ \\
\hline $\begin{array}{l}\text { EGFR and } \\
\text { HER2 }\end{array}$ & $\begin{array}{l}\text { Afatinib, Cetuximab, Erlotinib, Gefitinib, } \\
\text { Lapatinib, Necitumumab, Osimertinib, } \\
\text { Panitumumab, Vandetanib }\end{array}$ & $\begin{array}{l}\text { NSCLC, colorectal cancer, head and neck } \\
\text { cancer, pancreatic cancer, HER2 } 2^{+} \text {breast } \\
\text { cancer, medullary thyroid cancer }\end{array}$ & \\
\hline ALK & $\begin{array}{l}\text { Alectinib, Brigatinib, Ceritinib, } \\
\text { Crizotinib }\end{array}$ & NSCLC & \\
\hline mTOR & Everolimus, Temsirolimus & $\begin{array}{l}\mathrm{HR}^{+} \mathrm{HER} 2^{-} \text {breast cancer; renal cell } \\
\text { carcinoma; neuroendocrine tumors } \\
\text { originate from pancreas, gastrointestinal } \\
\text { tract, and lung }\end{array}$ & \\
\hline MEK & Cobimetinib, Trametinib & Melanoma, NSCLC & \\
\hline BRAF & Dabrafenib, Vemurafenib & Melanoma, NSCLC & \\
\hline $\mathrm{CDK} 4 / 6$ & Palbociclib, Ribociclib & $\mathrm{HR}^{+} \mathrm{HER} 2^{-}$breast cancer & Inhibit proliferation \\
\hline $\begin{array}{l}\text { VEGF/ } \\
\text { VEGFR }\end{array}$ & $\begin{array}{l}\text { Axitinib, Bevacizumab, Sunitinib, } \\
\text { Cabozantinib, Lenvatinib, Pazopanib, } \\
\text { Ramucirumab, Regorafenib, Sorafenib, } \\
\text { Ziv-aflibercept }\end{array}$ & $\begin{array}{l}\text { Renal cell carcinoma; cervival, colorectal, } \\
\text { fallopian tube, ovarian, peritoneal, } \\
\text { thyroid, and gastric cancers; giloblastoma; } \\
\text { hepatocelluolar carcinoma; NSCLC }\end{array}$ & Inhibit angiogenesis \\
\hline Smoothened & Sonidegib, Vismodegib & Basal cell carcinoma & Inhibit proliferation, \\
\hline PDGFR & Imatinib, Olaratumab; & $\begin{array}{l}\text { Gastrointestinal stroma tumor, soft tissue } \\
\text { sarcoma }\end{array}$ & $\begin{array}{l}\text { survival and } \\
\text { angiogenesis }\end{array}$ \\
\hline PARP & Niraparib, Olaparib, Rucaparib & $\begin{array}{l}\text { Fallopian tube, ovarian, and peritoneal } \\
\text { cancers }\end{array}$ & Induce DNA damage stress \\
\hline RANKL & Denosumab & $\begin{array}{l}\text { Bone giant cell tumor, multiple myeloma, } \\
\text { bone metastasis from soild tumors }\end{array}$ & $\begin{array}{l}\text { Inhibit osteoclast } \\
\text { differentiation and } \\
\text { activation }\end{array}$ \\
\hline B4GALNT1 & Dinutuximab & Pediatric neuroblastoma & $\begin{array}{l}\text { Induce metabolic stress } \\
\text { and supress angiogenesis }\end{array}$ \\
\hline IL-2 & Aldesleukin & Renal cell carcinoma, melanoma & Enhance \\
\hline PD-1/PD-L1 & $\begin{array}{l}\text { Atezolizumab, Avelumab, Durvalumab, } \\
\text { Nivolumab, Pembrolizumab }\end{array}$ & $\begin{array}{l}\text { Urothelial carcinoma, NSCLC, Merkel cell } \\
\text { carcinoma, colorectal cancer, head and } \\
\text { neck squamous cell carcinoma, } \\
\text { hepatocellular carcinoma, melanoma, } \\
\text { gastric cancer }\end{array}$ & immunosurveillance \\
\hline CTLA4 & Ipilimumab & Melanoma, renal cell carcinoma & \\
\hline
\end{tabular}

metastasis. Therapeutic strategies targeting CAFs have been developed for metastatic cancers (Fig. 1, CAFs). Sibrotuzumab, which is a humanized prolyl endopeptidase (FAP) monoclonal antibody targeting FAP in CAFs, is currently undergoing a phase II clinical trial for metastatic colon cancer (NCT02198274). However, no significant clinical benefit was observed. Subsequently, antiFAP conjugated with a cytotoxic drug maytansine (DM1) was developed. The resulting agent FAP5-DM1 delivers the cytotoxic drug DM1 specifically to CAFs to deplete the cells. Long-lasting tumor regression was observed upon FAP5-DM1 treatment in preclinical studies (Ostermann et al. 2008).

CAFs also secrete many factors, such as fibroblast growth factors (FGFs) to stimulate tumor cells and promote metastasis. The small molecule inhibitor Dovitinib, and monoclonal antibody GP369 against FGF receptors have achieved promising anti-tumor efficacy in preclinical and clinical studies (Bai et al. 2010; Musolino et al. 2017; NCT01528345).

\section{Reducing ECM stiffness}

In the stiffer ECM found in tumors, type 1 collagen and fibronectin are abundantly deposited to ECM in the tumor microenvironment (Cox and Erler 2011). In this regard, reducing stiffness by targeting collagen and fibronectin may inhibit tumor progression and metastasis (Fig. 1, ECM stiffness). All-trans retinoic acid, which can deactivate CAFs to reduce type 1 collagen production, is in clinical trials for cancer therapy (von Ahrens et al. 2017; NCT03999684 and NCT00001509|. Similarly, antibodies targeting fibronectin have been developed and tested for cancer therapy (Han and Lu 2017). Given the promising data in preclinical models, fibronectin targeting antibody L19 fused with TNF (L19-TNF) is also currently in clinical trials (NCT02076633 and NCT01213732; Hemmerle et al. 2013; Han and Lu 2017). Furthermore, inhibitors and antibodies that target ECM modifying enzymes, such as LOXs, are also in development (Winer et al. 2018), with preclinical data showing promising results that these inhibitors reduce breast cancer metastasis and 
enhance chemotherapy efficacy (Salvador et al. 2017; Saatci et al. 2020).

Moreover, instead of targeting ECM, therapeutic strategies that block ECM receptors in tumor cells to reinforce the original stiff stress have also been evaluated. In fact, many integrin antibodies and inhibitors are currently under clinical trials (Cianfrocca et al. 2006; Raab-Westphal et al. 2017). Another avenue uses natural ECM components with inhibitory functions for therapeutic purpose. For example, a recent study indicated that treatment of recombinant ECM protein Tinagl1 in mouse models inhibits breast cancer progression and metastasis by simultaneously blocking prometastatic signaling mediated by integrin $\alpha 5 \beta 1$ and EGFR (Shen et al. 2019).

\section{Targeting hypoxia}

Induced expression of HIFs allows tumor cells to escape hypoxic stress and gain metastatic abilities. Therapeutic agents that target HIFs have been developed and evaluated (Fig. 1, hypoxia). EZN-2968, which is an antisense oligonucleotide against HIF-1a mRNA expression, is currently under phase I clinical trial for refractory solid tumors (NCT01120288; Jeong et al. 2014). Similarly, Acriflavine, which inhibits HIF-1 dimerization, prevents tumor growth and EMT in in vitro and in vivo models (Lee et al. 2009; Dekervel et al. 2017). A phase I clinical trial of PT2385, a HIF-2 $\alpha$ antagonist, in advanced clear cell renal cell carcinoma showed that the drug has a favorable safety profile and significantly improves anti-tumor efficacy when combined with anti-PD-1 therapy (NCT02293980; Courtney et al. 2018). Another HIF-2 $\alpha$ antagonist, PT2399, also showed promising anti-tumor activity in a preclinical study (Courtney et al. 2020).

Instead of directly targeting HIFs, agents that block HIF's transcription activity, such as Chetomin and Bortezomib, are also under evaluation. For example, Bortezomib together with other therapeutics have been employed for phase I/II clinical trials in colorectal and prostate cancers (NCT01504477 and NCT00103376).

\section{Targeting metabolic reprogramming}

Metabolic enzymes are crucial for the altered metabolism in metastatic tumor cells. Targeting these enzymes could restore energy stress and suppress tumor progression and metastasis. 2-deoxyglucose, which targets hexokinase to reduce the excessive glycolysis commonly seen in tumors, has been employed in clinical trials for various cancers, with promising anti-tumor activities (NCT00633087 and NCT00096707; Dwarakanath et al. 2009; Stein et al. 2010). Lactate dehydrogenase A, which is essential for lactate production, has been found to be a poor prognostic marker for metastatic cancers (Mori et al. 2019; Pelizzari et al. 2019|. Preclinical study showed that targeting lactate dehydrogenase A has therapeutic potential (Le et al. 2010) (Fig. 1, metabolic reprogramming).

In addition to glycolysis, the TCA cycle is often altered in cancer. PDK is critical for the TCA cycle. The xenobiotic pyruvate analog dichloroacetate (DCA) can bind to
PDK and block its activity (Michelakis et al. 2008). Clinical trials of DCA in advanced colon and brain cancer patients achieved favorable outcomes (NCT01111097; Dunbar et al. 2014; Khan et al. 2016). Moreover, metformin, which influences the TCA cycle by targeting mitochondrial complex I, is an approved drug for type 2 diabetes. Interestingly, it has also been indicated to suppress cancer metastasis in preclinical studies (Karadeniz et al. 2020; Xie et al. 2020), and is now under clinical trials for cancer treatment (NCT01340300, NCT01697566, and NCT01717482; Kasznicki et al. 2014; Saraei et al. 2019).

\section{Refueling immune stress}

Although immune checkpoint blockade therapy has achieved remarkable success in some cancers, treatment resistance is commonly observed at late stage disease. Tumor cells have developed multiple resistance mechanisms to overcome the native or treatment-induced immune stress as described above. Targeting these resistant pathways to restore immune stress is crucial to sustain immune therapy responses. To this end, therapeutic strategies targeting $\mathrm{T}$ cells or tumor intrinsic immune stress-relieving pathways have been developed and are under preclinical/clinical evaluations (Fig. 1, immunosurveillance).

To restore or enhance immune cell activity in tumors to suppress metastasis, $\mathrm{T}$ cells isolated from patients are genetically engineered and reinfused. Chimeric antibody receptor engineered T-cell (CAR-T) and genetically modified T-cell receptors (TCR-T) are two main technologies used in this regard, which improve the ability of $\mathrm{T}$ cells in tumor recognition and killing. CAR-T has been approved for lymphoma treatment.

Moreover, both CAR-T and TCR-T are under numerous clinical trials for solid tumor treatments, and promising results have been observed in some cases (Zhang and Wang 2019; Fucà et al. 2020).

Activation of additional inhibitory immune checkpoint pathways is one of the most common strategies that tumor cells employ to release immune stress. To reduce T-cell exhaustion, antibodies that target additional checkpoints have been developed and are under clinical trials, such as VISTA (NCT02812875), TIM-3 (NCT03489343), LAG-3 (NCT00351949), TIGIT (NCT03945253), and B7H3 (NCT02923180) (Qin et al. 2019).

In addition to these well-established targets, a new immunosuppressive checkpoint Siglec-15 has also been identified and proven to be essential for metastasis (Takamiya et al. 2013; Wang et al. 2019a). Targeting Siglec-15 showed promising results in both preclinical and clinical studies (Wang et al. 2019a). Moreover, as CD38 of T cells mediates PD-1/PD-L1 blockade resistance and enhances metastasis (Chen et al. 2018), coinhibition of CD38 and PD-L1 could improve the anti-metastasis effects.

In addition to developing new T-cell surface targets, high-throughput screenings have been performed to identify novel intracellular candidates to boost T-cell activity. Previous studies found that RNA helicase Dhx37 and endoribonuclease REGNASE-1 modulate $\mathrm{CD}^{+} \mathrm{T}$-cell 
activation through the NF-кB pathway and by targeting BATF, respectively, to promote metastasis (Dong et al. 2019a; Wei et al. 2019). This suggests that Dhx37 and REGNASE-1 could serve as new targets to reinforce immune stress and suppresses metastasis.

On the other hand, targeting tumor-intrinsic pathways to overcome the immune checkpoint blockade therapy resistance could also restore immune stress. Given that PTEN loss induced PI3K-AKT activation results in immunotherapy resistance, PI3K $\beta$ inhibitor treatment significantly improved the anti-PD-1 and anti-CTLA4 efficacy in mouse models (Peng et al. 2016). Enhancing tumor antigenicity is another strategy to elevate immunosurveillance. To this end, a modified herpes simplex virus that infects tumor cells and promotes their destruction to enhance immune response has been approved for melanoma treatment. More oncolytic viruses are currently under clinical trials (Mondal et al. 2020). Moreover, elevating antigen presentation of tumor cells could also increase tumor antigenicity and enhance immune stress. Jaeger et al. (2019) found that low-level inhibition of HSP90 amplifies and diversifies the antigenic repertoire presented by tumor cells on MHC class I molecules, suggesting that targeting HSP90 in tumor cells could serve as a novel immunotherapeutic approach. In line with this notion, five HSP90 inhibitors are currently under clinical evaluation for cancer therapy (Yuno et al. 2018). Epigenetically, histone deacetylases have been found to down-regulate HLA class I expression and inhibit antigen processing and presentation (Ritter et al. 2017). Consistently, the histone deacetylase inhibitor Panobinostat was found to elevate $\mathrm{CD}^{+} \mathrm{T}$-cell infiltration in association with PD-1/PD-L1 blockade treatment in metastatic Merkel cell carcinoma patients (Ugurel et al. 2019).

\section{Targeting anoikis resistance and releasing fluid shear stress}

Preclinical studies indicated that DZ-50, which is a quinazoline-based al adrenoceptor antagonist Doxazosin-derived compound, significantly inhibits prostate cancer metastasis by targeting anoikis resistance (Garrison et al. 2007; Hensley et al. 2014). T0070907, which is a peroxisome proliferator-activated receptor $\gamma(\operatorname{PPAR} \gamma)$ inhibitor, has been showed to inhibit cancer progression and metastasis by reverting anoikis resistance in hepatocellular carcinoma and breast cancer models (Schaefer et al. 2005; Zaytseva et al. 2011). Moreover, talin1 has also been reported to promote prostate cancer metastasis by conferring anoikis resistance (Sakamoto et al. 2010), indicating the therapeutic potential of targeting this protein. Collectively, these results indicate that targeting anoikis resistance could be feasible as an anti-metastasis treatment (Fig. 2).

Mechanosensing carriers, such as liposomes and microaggregates that can respond to shear stress have been developed for cardiovascular disease treatment (Wang et al. 2017). Such shear-activated systems could specificity deliver anti-tumor drugs to malignant cells that are under shear stress. However, there are still many technical chal- lenges that need to be overcome before clinical success of such applications.

\section{Restoring metastatic-organ specific stresses}

Most existing cancer treatments do not distinguish tumors residing in different metastatic organ sites. However, some organs, such as the brain and bone, have unique structures and microenvironments that are distinct from the rest of the body, suggesting that organ-specific strategies could be developed to reduce metastasis. Moreover, accumulating knowledge about the mechanisms underlying organ-specific metastasis also provides insights into the development of such anti-metastasis therapeutics.

For brain metastasis, reinforcing the blood-brain barrier could decrease the risk of brain colonization. In this regard, molecules that mediate the blood-brain barrier transmigration serve as attractive targets. Preclinical studies suggested that treatment with the protease inhibitor Pefabloc reduces the crossing of the blood-brain barrier by tumor cells and reduces brain metastasis in preclinical models of melanoma (Fazakas et al. 2011). Astrocytes have been recognized as an essential stromal contributor to brain metastasis (Chen et al. 2016; Priego et al. 2018), and previous studies indicated that STAT3 activation in astrocytes is required for brain colonization (Priego et al. 2018). Treatment with silibinin, a STAT3 inhibitor, significantly impairs astrocytes and decreases brain metastasis in both mouse models and patients (Priego et al. 2018).

As tumor cells hijack functions of osteoblasts and osteoclasts to disrupt bone homeostasis and to enhance osteolytic or osteoblastic metastasis, bone stromal cell targeting agents, such as bisphosphonates and the RANKLneutralizing antibody Denosumab, have been used for relieve complications from bone metastasis (Holen and Coleman 2010). However, these treatments do not improve overall survival and have significant severe side effects in patients such as jaw necrosis and renal toxicity.

Recent studies indicated that Notch signaling is involved in bone metastasis (Sethi et al. 2011; Sethi and Kang 2011). In breast cancer, the Notch ligand Jagged1 promotes osteoclast maturation and activates osteoblasts to increase the production of IL-6, which in turn promotes tumor progression and bone metastasis (Sethi et al. 2011). Chemotherapy-induced Jagged1 in osteogenic cells further provides a protective niche for tumor cells in bone (Zheng et al. 2017). A fully humanized monoclonal antibody against Jagged-1 (Zheng et al. 2017) effectively blocks Notch signaling with minimal toxicity in vivo. Importantly, treatment with the antibody significantly reduces bone metastasis and synergistically enhances chemotherapy efficacy in mouse models (Fig. 3D; Zheng et al. 2017).

\section{Concluding remarks and perspectives}

The emergence, growth, and metastatic spread of malignant tumors has been viewed as a continuous attrition 
process that selects for clonal or heterogeneous populations of cancer cells that survive and thrive against all odds. Such clones with enhanced fitness not only can survive the cancer-specific stresses better, but often gain increased metastatic potentials. This is not only because of their overall survival fitness but also as a consequence of prometastatic genes and pathways activated by stress-relieving pathways, as discussed in this review. It is therefore not surprising that metastasis fitness genes might be already giving tumor cells a survival advantage in the primary tumors, and allows their enrichment in the expanding clonal populations that eventually seed distant metastasis. This view of metastasis as a by-product of stress-coping mechanisms questions the traditionally self-imposed requirement of the field, that "metastasis genes" always have to be strongly enriched in metastatic lesions compared with the primary tumor. This concept is in line with the fact that there have not been metastasis-specific genetic mutations identified by genomic sequencing of human cancers (Vogelstein et al. 2013), and that gene expression profile of primary tumors can predict the risk of metastasis (van 't Veer et al. 2002).

It is also worth noting that such fitness-boosting genes may use distinct mechanisms or engage different stromal populations at different organ sites during cancer progression. For example, RANKL has been shown to be essential for the expansion of mammary gland progenitors during mammary gland development and is also critical in the initiation of BRCA1 mutation-driven breast cancer (Nolan et al. 2016; Sigl et al. 2016). Once reaching the bone, tumor-derived RANKL stimulates osteoclastogenesis and the development of osteolytic lesions. Likewise, Jagged 1 promotes primary tumor growth through increasing proliferation, chemoresistance and angiogenesis (Xiu et al. 2020) while exacerbating bone metastasis by engaging Notch signaling in osteoblasts and osteoclasts (Sethi et al. 2011). Such multi-functional fitness promoting factors represent ideal therapeutic targets given their involvement in different stages of cancer progression.

The present review summarizes some of the key pathways involved in stress-relief during metastatic progression. However, this is by no means a comprehensive compilation of all major mechanisms known to date. Additional and critical stress pathways such as oxidative stress and ER stress are likely to play key roles in modulating metastatic efficiency but are not covered here due to space limitations. Furthermore, all these pathways are interconnected by complex feedback regulations. For instance, the interplay among hypoxia, metabolic stress, and immunosurveillance has been well recognized (Krzywinska and Stockmann 2018; Petrova et al. 2018). The interconnected nature of the stress-relief pathways implies the possibility of targeting key regulatory nodes to achieve simultaneous disruption of multiple pathways, but also indicates potential risk of therapeutic escape by compensational feedback mechanisms. Nevertheless, the clinical success of immune checkpoint blockade therapy and synthetic lethal treatment of BRCA-defi- cient cancers with PARP inhibitors underscores the potential of dramatic clinical response when a key antitumor stress mechanism is restored. Notably, many such therapies are well tolerated by healthy tissues as the targeted stress-relief mechanisms are more critically required for malignant tissues. With rapid increase in the knowledge of metastatic stress pathways and metastasis fitness genes, we can anticipate additional breakthroughs in coming years in the prevention and control of metastatic cancers.

\section{Competing interest statement}

Y.K. holds equity interest in KayoThera and Firebrand Therapeutics, and is a member of Scientific Advisory Boards of Kayothera, Firebrand Therapeutics, Cytocares and FrontAim.

\section{Acknowledgments}

We thank the members of our laboratory for helpful discussions. We also apologize to the many investigators whose important studies could not be cited directly here owing to space limitations. The work was supported by the postdoctoral fellowships from the Susan G. Komen Foundation and the New Jersey Commission on Cancer Research to M.S., and grants from the Brewster Foundation, the American Cancer Society, the Susan G. Komen Foundation, the Breast Cancer Research Foundation, the National Institutes of Health, and the U.S. Department of Defense to Y.K.

\section{References}

Aceto N, Bardia A, Miyamoto DT, Donaldson MC, Wittner BS, Spencer JA, Yu M, Pely A, Engstrom A, Zhu H, et al. 2014. Circulating tumor cell clusters are oligoclonal precursors of breast cancer metastasis. Cell 158: 1110-1122. doi:10.1016/j .cell.2014.07.013

Aguirre Ghiso JA. 2002. Inhibition of FAK signaling activated by urokinase receptor induces dormancy in human carcinoma cells in vivo. Oncogene 21: 2513-2524. doi:10.1038/sj.onc .1205342

Aguirre-Ghiso JA. 2007. Models, mechanisms and clinical evidence for cancer dormancy. Nat Rev Cancer 7: 834-846. doi: $10.1038 / \mathrm{nrc} 2256$

Aiello NM, Kang Y. 2019. Context-dependent EMT programs in cancer metastasis. J Exp Med 216: 1016-1026. doi:10.1084/ jem.20181827

Andrews LP, Marciscano AE, Drake CG, Vignali DA. 2017. LAG3 (CD223) as a cancer immunotherapy target. Immunol ReV 276: 80-96. doi:10.1111/imr.12519

Bai A, Meetze K, Vo NY, Kollipara S, Mazsa EK, Winston WM, Weiler S, Poling LL, Chen T, Ismail NS, et al. 2010. GP369, an FGFR2-IIIb-specific antibody, exhibits potent antitumor activity against human cancers driven by activated FGFR 2 signaling. Cancer Res 70: 7630-7639. doi:10.1158/0008-5472 .CAN-10-1489

Banerjee D, Hernandez SL, Garcia A, Kangsamaksin T, Sbiroli E, Andrews J, Forrester LA, Wei N, Kadenhe-Chiweshe A, Shawber CJ, et al. 2015. Notch suppresses angiogenesis and progression of hepatic metastases. Cancer Res 75: 15921602. doi:10.1158/0008-5472.CAN-14-1493 
Barkan D, El Touny LH, Michalowski AM, Smith JA, Chu I, Davis AS, Webster JD, Hoover S, Simpson RM, Gauldie J, et al. 2010. Metastatic growth from dormant cells induced by a col-I-enriched fibrotic environment. Cancer Res 70: 5706-5716. doi:10.1158/0008-5472.CAN-09-2356

Barrow AD, Edeling MA, Trifonov V, Luo J, Goyal P, Bohl B, Bando JK, Kim AH, Walker J, Andahazy M, et al. 2018. Natural killer cells control tumor growth by sensing a growth factor. Cell 172: 534-548.e19. doi:10.1016/j.cell.2017.11.037

Becker LM, O'Connell JT, Vo AP, Cain MP, Tampe D, Bizarro L, Sugimoto H, McGow AK, Asara JM, Lovisa S, et al. 2020. Epigenetic reprogramming of cancer-associated fibroblasts deregulates glucose metabolism and facilitates progression of breast cancer. Cell Rep 31: 107701. doi:10.1016/j.celrep.2020.107701

Bhardwaj V, He J. 2020. Reactive oxygen species, metabolic plasticity, and drug resistance in cancer. Int J Mol Sci 21: 3412. doi:10.3390/ijms21103412

Braet F, Nagatsuma K, Saito M, Soon L, Wisse E, Matsuura T. 2007. The hepatic sinusoidal endothelial lining and colorectal liver metastases. World I Gastroenterol 13: 821-825. doi:10 .3748/wig.v13.i6.821

Brodt P. 2016. Role of the microenvironment in liver metastasis: from pre- to prometastatic niches. Clin Cancer Res 22: 59715982. doi:10.1158/1078-0432.CCR-16-0460

Brodt P, Fallavollita L, Bresalier RS, Meterissian S, Norton CR, Wolitzky BA. 1997. Liver endothelial E-selectin mediates carcinoma cell adhesion and promotes liver metastasis. Int J Cancer 71: 612-619. doi:10.1002/(SICI)1097-0215(19970516)71 $: 4<612::$ AID-IJC17>3.0.CO;2-D

Caino MC, Chae YC, Vaira V, Ferrero S, Nosotti M, Martin NM, Weeraratna A, O'Connell M, Jernigan D, Fatatis A, et al. 2013. Metabolic stress regulates cytoskeletal dynamics and metastasis of cancer cells. J Clin Invest 123: 2907-2920. doi:10 $.1172 / \mathrm{JCI} 67841$

Cao Y, Zhou X, Huang X, Li Q, Gao L, Jiang L, Huang M, Zhou J. 2013. Tim-3 expression in cervical cancer promotes tumor metastasis. PLOS One 8: e53834. doi:10.1371/journal.pone .0053834

Carreau A, El Hafny-Rahbi B, Matejuk A, Grillon C, Kieda C. 2011. Why is the partial oxygen pressure of human tissues a crucial parameter? Small molecules and hypoxia. J Cell Mol Med 15: 1239-1253. doi:10.1111/j.1582-4934.2011.01258.x

Celià-Terrassa T, Kang Y. 2016. Distinctive properties of metastasis-initiating cells. Genes Dev 30: 892-908. doi:10.1101/gad .277681 .116

Chambers AF, Groom AC, MacDonald IC. 2002. Dissemination and growth of cancer cells in metastatic sites. Nat Rev Cancer 2: 563-572. doi:10.1038/nrc865

Chen Q, Zhang XH, Massagué J. 2011. Macrophage binding to receptor VCAM-1 transmits survival signals in breast cancer cells that invade the lungs. Cancer Cell 20: 538-549. doi:10 $.1016 /$ j.ccr.2011.08.025

Chen Q, Boire A, Jin X, Valiente M, Er EE, Lopez-Soto A, Jacob L, Patwa R, Shah H, Xu K, et al. 2016. Carcinoma-astrocyte gap junctions promote brain metastasis by cGAMP transfer. $\mathrm{Na}$ ture 533: 493-498. doi:10.1038/nature 18268

Chen L, Diao L, Yang Y, Yi X, Rodriguez BL, Li Y, Villalobos PA, Cascone T, Liu X, Tan L, et al. 2018. CD38-Mediated immunosuppression as a mechanism of tumor cell escape from PD-1/PD-L1 blockade. Cancer Discov 8: 1156-1175. doi:10 .1158/2159-8290.CD-17-1033

Chen Z, Zhang P, Xu Y, Yan J, Liu Z, Lau WB, Lau B, Li Y, Zhao X, Wei $Y$, et al. 2019. Surgical stress and cancer progression: the twisted tango. Mol Cancer 18: 132. doi:10.1186/s12943-0191058-3
Cianfrocca ME, Kimmel KA, Gallo J, Cardoso T, Brown MM, Hudes G, Lewis N, Weiner L, Lam GN, Brown SC, et al. 2006. Phase 1 trial of the antiangiogenic peptide ATN-161 (Ac-PHSCN-NH $\mathrm{N}_{2}$ ), a $\beta$ integrin antagonist, in patients with solid tumours. Br J Cancer 94: 1621-1626. doi:10.1038/sj.bjc .6603171

Cognart HA, Viovy JL, Villard C. 2020. Fluid shear stress coupled with narrow constrictions induce cell type-dependent morphological and molecular changes in SK-BR-3 and MDA-MB231 cells. Sci Rep 10: 6386. doi:10.1038/s41598-020-63316-w

Conrad C, Götte M, Schlomann U, Roessler M, Pagenstecher A, Anderson P, Preston J, Pruessmeyer J, Ludwig A, Li R, et al. 2018. ADAM8 expression in breast cancer derived brain metastases: functional implications on MMP-9 expression and transendothelial migration in breast cancer cells. Int J Cancer 142: 779-791. doi:10.1002/ijc.31090

Courtney KD, Infante JR, Lam ET, Figlin RA, Rini BI, Brugarolas J, Zojwalla NJ, Lowe AM, Wang K, Wallace EM, et al. 2018. Phase I dose-escalation trial of PT2385, a first-in-class hypoxia-inducible factor- $2 \alpha$ antagonist in patients with previously treated advanced clear cell renal cell carcinoma. J Clin Oncol 36: 867-874. doi:10.1200/JCO.2017.74.2627

Courtney KD, Ma Y, Diaz de Leon A, Christie A, Xie Z, Woolford L, Singla N, Joyce A, Hill H, Madhuranthakam AJ, et al. 2020. HIF-2 complex dissociation, target inhibition, and acquired resistance with PT2385, a first-in-class HIF-2 inhibitor, in patients with clear cell renal cell carcinoma. Clin Cancer Res 26: 793-803. doi:10.1158/1078-0432.CCR-19-1459

Cox TR, Erler JT. 2011. Remodeling and homeostasis of the extracellular matrix: implications for fibrotic diseases and cancer. Dis Model Mech 4: 165-178. doi:10.1242/dmm.004077

Croucher PI, McDonald MM, Martin TJ. 2016. Bone metastasis: the importance of the neighbourhood. Nat Rev Cancer 16: 373-386. doi:10.1038/nrc.2016.44

Cruz-Munoz W, Khokha R. 2008. The role of tissue inhibitors of metalloproteinases in tumorigenesis and metastasis. Crit Rev Clin Lab Sci 45: 291-338. doi:10.1080/10408360801973244

Das M, Zhu C, Kuchroo VK. 2017. Tim-3 and its role in regulating anti-tumor immunity. Immunol Rev 276: 97-111. doi:10 $.1111 /$ imr. 12520

Dekervel J, Bulle A, Windmolders P, Lambrechts D, Van Cutsem E, Verslype C, van Pelt J. 2017. Acriflavine inhibits acquired drug resistance by blocking the epithelial-to-mesenchymal transition and the unfolded protein response. Transl Oncol 10: 59-69. doi:10.1016/j.tranon.2016.11.008

Derksen PW, Liu X, Saridin F, van der Gulden H, Zevenhoven J, Evers B, van Beijnum JR, Griffioen AW, Vink J, Krimpenfort $\mathrm{P}$, et al. 2006. Somatic inactivation of E-cadherin and p53 in mice leads to metastatic lobular mammary carcinoma through induction of anoikis resistance and angiogenesis. Cancer Cell 10: 437-449. doi:10.1016/j.ccr.2006.09.013

Dong MB, Wang G, Chow RD, Ye L, Zhu L, Dai X, Park JJ, Kim HR, Errami Y, Guzman CD, et al. 2019a. Systematic immunotherapy target discovery using genome-scale In vivo CRISPR screens in CD8 T cells. Cell 178: 1189-1204.e23. doi:10 .1016/j.cell.2019.07.044

Dong Y, Zheng Q, Wang Z, Lin X, You Y, Wu S, Wang Y, Hu C, Xie $X$, Chen J, et al. 2019b. Higher matrix stiffness as an independent initiator triggers epithelial-mesenchymal transition and facilitates HCC metastasis. J Hematol Oncol 12: 112. doi:10 .1186/s13045-019-0795-5

Douma S, Van Laar T, Zevenhoven J, Meuwissen R, Van Garderen E, Peeper DS. 2004. Suppression of anoikis and induction of metastasis by the neurotrophic receptor trkB. Nature 430: 1034-1039. doi:10.1038/nature02765 
Dumont N, Liu B, Defilippis RA, Chang H, Rabban JT, Karnezis AN, Tjoe JA, Marx J, Parvin B, Tlsty TD. 2013. Breast fibroblasts modulate early dissemination, tumorigenesis, and metastasis through alteration of extracellular matrix characteristics. Neoplasia 15: 249-262. doi:10.1593/neo .121950

Dunbar EM, Coats BS, Shroads AL, Langaee T, Lew A, Forder JR, Shuster JJ, Wagner DA, Stacpoole PW. 2014. Phase 1 trial of dichloroacetate (DCA) in adults with recurrent malignant brain tumors. Invest New Drugs 32: 452-464. doi:10.1007/ s10637-013-0047-4

Dupont S, Morsut L, Aragona M, Enzo E, Giulitti S, Cordenonsi M, Zanconato F, Le Digabel J, Forcato M, Bicciato S, et al. 2011. Role of YAP/TAZ in mechanotransduction. Nature 474: 179-183. doi:10.1038/nature 10137

Dwarakanath BS, Singh D, Banerji AK, Sarin R, Venkataramana NK, Jalali R, Vishwanath PN, Mohanti BK, Tripathi RP, Kalia $\mathrm{VK}$, et al. 2009. Clinical studies for improving radiotherapy with 2-deoxy-D-glucose: present status and future prospects. I Cancer Res Ther 5: S21-S26. doi:10.4103/0973-1482.55136

Egeblad M, Rasch MG, Weaver VM. 2010. Dynamic interplay between the collagen scaffold and tumor evolution. Curr Opin Cell Biol 22: 697-706. doi:10.1016/j.ceb.2010.08.015

Erler JT, Bennewith KL, Cox TR, Lang G, Bird D, Koong A, Le QT, Giaccia AJ. 2009. Hypoxia-induced lysyl oxidase is a critical mediator of bone marrow cell recruitment to form the premetastatic niche. Cancer Cell 15: 35-44. doi:10.1016/j.ccr.2008 .11 .012

Esposito M, Mondal N, Greco TM, Wei Y, Spadazzi C, Lin SC, Zheng H, Cheung C, Magnani JL, Lin SH, et al. 2019. Bone vascular niche E-selectin induces mesenchymal-epithelial transition and Wnt activation in cancer cells to promote bone metastasis. Nat Cell Biol 21: 627-639. doi:10.1038/s41556019-0309-2

Fabbri M, Paone A, Calore F, Galli R, Gaudio E, Santhanam R, Lovat F, Fadda P, Mao C, Nuovo GJ, et al. 2012. MicroRNAs bind to toll-like receptors to induce prometastatic inflammatory response. Proc Natl Acad Sci 109: E2110-E2116. doi:10 $.1073 /$ pnas.1209414109

Fares J, Kanojia D, Rashidi A, Ulasov I, Lesniak MS. 2020. Genes that mediate metastasis across the blood-brain barrier. Trends Cancer 6: 660-676. doi:10.1016/j.trecan.2020.04.007

Fazakas C, Wilhelm I, Nagyőszi P, Farkas AE, Haskó J, Molnár J, Bauer H, Bauer HC, Ayaydin F, Dung NT, et al. 2011. Transmigration of melanoma cells through the blood-brain barrier: role of endothelial tight junctions and melanoma-released serine proteases. PLoS One 6: e20758. doi:10.1371/journal.pone .0020758

Fofaria NM, Srivastava SK. 2015. STAT3 induces anoikis resistance, promotes cell invasion and metastatic potential in pancreatic cancer cells. Carcinogenesis 36: 142-150. doi:10.1093/ carcin/bgu233

Follain G, Herrmann D, Harlepp S, Hyenne V, Osmani N, Warren SC, Timpson P, Goetz JG. 2020. Fluids and their mechanics in tumour transit: shaping metastasis. Nat Rev Cancer 20: 107124. doi:10.1038/s41568-019-0221-x

Fortunato L, Mascaro A, Baldi A, Farina M, Cortese G, Ventrone MA, Amini M, Vitelli C. 2009. Positive bone marrow biopsy is associated with a decreased disease-free survival in patients with operable breast cancer. Ann Surg Oncol 16: 3010-3019. doi:10.1245/s10434-009-0619-x

Frantz C, Stewart KM, Weaver VM. 2010. The extracellular matrix at a glance. I Cell Sci 123: 4195-4200. doi:10.1242/jcs .023820
Fucà G, Reppel L, Landoni E, Savoldo B, Dotti G. 2020. Enhancing chimeric antigen receptor T-cell efficacy in solid tumors. Clin Cancer Res 26: 2444-2451. doi:10.1158/1078-0432 .CCR-19-1835

Fuchs BC, Fujii T, Dorfman JD, Goodwin JM, Zhu AX, Lanuti M, Tanabe KK. 2008. Epithelial-to-mesenchymal transition and integrin-linked kinase mediate sensitivity to epidermal growth factor receptor inhibition in human hepatoma cells. Cancer Res 68: 2391-2399. doi:10.1158/0008-5472 .CAN-07-2460

Gao J, Ward JF, Pettaway CA, Shi LZ, Subudhi SK, Vence LM, Zhao H, Chen J, Chen H, Efstathiou E, et al. 2017. VISTA is an inhibitory immune checkpoint that is increased after ipilimumab therapy in patients with prostate cancer. Nat Med 23: 551-555. doi:10.1038/nm.4308

Garrido F, Aptsiauri N. 2019. Cancer immune escape: MHC expression in primary tumours versus metastases. Immunology 158: $255-266$. doi:10.1111/imm.13114

Garrison JB, Shaw YJ, Chen CS, Kyprianou N. 2007. Novel quinazoline-based compounds impair prostate tumorigenesis by targeting tumor vascularity. Cancer Res 67: 11344-11352. doi:10.1158/0008-5472.CAN-07-1662

Gay LJ, Felding-Habermann B. 2011. Contribution of platelets to tumour metastasis. Nat Rev Cancer 11: 123-134. doi:10.1038/ nrc3004

Ghanbari Movahed Z, Rastegari-Pouyani M, Mohammadi MH, Mansouri K. 2019. Cancer cells change their glucose metabolism to overcome increased ROS: one step from cancer cell to cancer stem cell? Biomed Pharmacother 112: 108690. doi:10 $.1016 /$ j.biopha.2019.108690

Goncalves MD, Hopkins BD, Cantley LC. 2018. Phosphatidylinositol 3-kinase, growth disorders, and cancer. N Engl J Med 379: 2052-2062. doi:10.1056/NEJMra1704560

González L, Eiro N, Fernandez-Garcia B, González LO, Dominguez F, Vizoso FJ. 2016. Gene expression profile of normal and cancer-associated fibroblasts according to intratumoral inflammatory cells phenotype from breast cancer tissue. Mol Carcinog 55: 1489-1502. doi:10.1002/mc.22403

Griesenauer RH, Weis JA, Arlinghaus LR, Meszoely IM, Miga MI. 2017. Breast tissue stiffness estimation for surgical guidance using gravity-induced excitation. Phys Med Biol 62: 47564776. doi:10.1088/1361-6560/aa700a

Groulx I, Lee S. 2002. Oxygen-dependent ubiquitination degradation of hypoxia-inducible factor requires nuclear-cytoplasmic trafficking of the von Hippel-Lindau tumor suppressor protein. Mol Cell Biol 22: 5319-5336. doi:10.1128/mcb.22.15 $.5319-5336.2002$

Gupta GP, Massagué J. 2006. Cancer metastasis: building a framework. Cell 127: 679-695. doi:10.1016/j.cell.2006.11.001

Han Z, Lu ZR. 2017. Targeting fibronectin for cancer imaging and therapy. I Mater Chem B 5: 639-654. doi:10.1039/ C6TB02008A

Hanahan D, Weinberg RA. 2011. Hallmarks of cancer: the next generation. Cell 144: 646-674. doi:10.1016/j.cell.2011.02.013

Hayakawa Y, Ariyama H, Stancikova J, Sakitani K, Asfaha S, Renz BW, Dubeykovskaya ZA, Shibata W, Wang H, Westphalen CB, et al. 2015. Mist1 expressing gastric stem cells maintain the normal and neoplastic gastric epithelium and are supported by a perivascular stem cell niche. Cancer Cell 28: 800-814. doi:10.1016/j.ccell.2015.10.003

Hemmerle T, Probst P, Giovannoni L, Green AJ, Meyer T, Neri D. 2013. The antibody-based targeted delivery of TNF in combination with doxorubicin eradicates sarcomas in mice and confers protective immunity. Br J Cancer 109: 1206-1213. doi:10 $.1038 /$ bjc. 2013.421 
Hensley PJ, Desiniotis A, Wang C, Stromberg A, Chen CS, Kyprianou N. 2014. Novel pharmacologic targeting of tight junctions and focal adhesions in prostate cancer cells. PLoS One 9: e86238. doi:10.1371/journal.pone.0086238

Holen I, Coleman RE. 2010. Bisphosphonates as treatment of bone metastases. Curr Pharm Des 16: 1262-1271. doi:10 $.2174 / 138161210791034003$

Holmgren L, O’Reilly MS, Folkman J. 1995. Dormancy of micrometastases: balanced proliferation apoptosis in the presence of angiogenesis suppression. Nat Med 1: 149-153. doi:10.1038/ nm0295-149

Hu JL, Wang W, Lan XL, Zeng ZC, Liang YS, Yan YR, Song FY, Wang FF, Zhu XH, Liao WJ, et al. 2019a. CAFs secreted exosomes promote metastasis and chemotherapy resistance by enhancing cell stemness and epithelial-mesenchymal transition in colorectal cancer. Mol Cancer 18: 91. doi:10.1186/ s12943-019-1019-x

Hu Q, Ye Y, Chan LC, Li Y, Liang K, Lin A, Egranov SD, Zhang Y, Xia W, Gong J, et al. 2019b. Oncogenic lncRNA downregulates cancer cell antigen presentation and intrinsic tumor suppression. Nat Immunol 20: 835-851. doi:10.1038/s41590-0190400-7

Huang Q, Li S, Hu X, Sun M, Wu Q, Dai H, Tan Y, Sun F, Wang C, Rong X, et al. 2020. Shear stress activates ATOH8 via autocrine VEGF promoting glycolysis dependent-survival of colorectal cancer cells in the circulation. J Exp Clin Cancer Res 39: 25. doi:10.1186/s13046-020-1533-0

Hynes RO. 2009. The extracellular matrix: not just pretty fibrils. Science 326: 1216-1219. doi:10.1126/science.1176009

Iwamura M, Hellman J, Cockett ATK, Lilja H, Gershagen S. 1996. Alteration of the hormonal bioactivity of parathyroid hormone-related protein $(\mathrm{PTHrP})$ as a result of limited proteolysis by prostate-specific antigen. Urology 48: 317-325. doi:10 .1016/S0090-4295(96)00182-3

Jaeger AM, Stopfer L, Lee S, Gaglia G, Sandel D, Santagata S, Lin NU, Trepel JB, White F, Jacks T, et al. 2019. Rebalancing protein homeostasis enhances tumor antigen presentation. Clin Cancer Res 25: 6392-6405. doi:10.1158/1078-0432.CCR-190596

Jansen VM, Bhola NE, Bauer JA, Formisano L, Lee KM, Hutchinson KE, Witkiewicz AK, Moore PD, Estrada MV, Sánchez V, et al. 2017. Kinome-Wide RNA interference screen reveals a role for PDK1 in acquired resistance to CDK4/6 inhibition in ER-positive breast cancer. Cancer Res 77: 2488-2499. doi:10.1158/0008-5472.CAN-16-2653

Jeong W, Rapisarda A, Park SR, Kinders RJ, Chen A, Melillo G, Turkbey B, Steinberg SM, Choyke P, Doroshow JH, et al. 2014. Pilot trial of EZN-2968, an antisense oligonucleotide inhibitor of hypoxia-inducible factor-1 a (HIF-1a), in patients with refractory solid tumors. Cancer Chemother Pharmacol 73: 343-348. doi:10.1007/s00280-013-2362-z

Johnson RW, Nguyen MP, Padalecki SS, Grubbs BG, Merkel AR, Oyajobi BO, Matrisian LM, Mundy GR, Sterling JA. 2011. TGF- $\beta$ promotion of Gli2-induced expression of parathyroid hormone-related protein, an important osteolytic factor in bone metastasis, is independent of canonical hedgehog signaling. Cancer Res 71: 822-831. doi:10.1158/0008-5472.CAN10-2993

Joyce JA, Pollard JW. 2009. Microenvironmental regulation of metastasis. Nat Rev Cancer 9: 239-252. doi:10.1038/nrc2618

Jung M, Mertens C, Bauer R, Rehwald C, Brüne B. 2017. Lipocalin-2 and iron trafficking in the tumor microenvironment. Pharmacol Res 120: 146-156. doi:10.1016/j.phrs.2017.03.018
Kang Y, Pantel K. 2013. Tumor cell dissemination: emerging biological insights from animal models and cancer patients. Cancer Cell 23: 573-581. doi:10.1016/j.ccr.2013.04.017

Kang HS, Kwon HY, Kim IK, Ban WH, Kim SW, Kang HH, Yeo CD, Lee SH. 2020. Intermittent hypoxia exacerbates tumor progression in a mouse model of lung cancer. Sci Rep 10: 1854. doi:10.1038/s41598-020-58906-7

Karadeniz Z, Aynacioğlu AS, Bilir A, Tuna MY. 2020. Inhibition of midkine by metformin can contribute to its anticancer effects in malignancies: a proposal mechanism of action of metformin in context of endometrial cancer prevention and therapy. Med Hypotheses 134: 109420. doi:10.1016/j.mehy .2019 .109420

Kasznicki J, Sliwinska A, Drzewoski J. 2014. Metformin in cancer prevention and therapy. Ann Transl Med 2: 57.

Ke Q, Costa M. 2006. Hypoxia-inducible factor-1 (HIF-1). Mol Pharmacol 70: 1469-1480. doi:10.1124/mol.106.027029

Khan A, Andrews D, Blackburn AC. 2016. Long-term stabilization of stage 4 colon cancer using sodium dichloroacetate therapy. World I Clin Cases 4: 336-343. doi:10.12998/wjcc .v4.i10.336

Kim BG, Gao MQ, Kang S, Choi YP, Lee JH, Kim JE, Han HH, Mun SG, Cho NH. 2017. Mechanical compression induces VEGFA overexpression in breast cancer via DNMT3A-dependent miR-9 downregulation. Cell Death Dis 8: e2646. doi:10 $.1038 /$ cddis. 2017.73

Kimura Y, Inoue A, Hangai S, Saijo S, Negishi H, Nishio J, Yamasaki S, Iwakura Y, Yanai H, Taniguchi T. 2016. The innate immune receptor dectin-2 mediates the phagocytosis of cancer cells by kupffer cells for the suppression of liver metastasis. Proc Natl Acad Sci 113: 14097-14102. doi:10.1073/pnas .1617903113

Kloor M, Michel S, von Knebel Doeberitz M. 2010. Immune evasion of microsatellite unstable colorectal cancers. Int J Cancer 127: 1001-1010. doi:10.1002/ijc.25283

Knott SRV, Wagenblast E, Khan S, Kim SY, Soto M, Wagner M, Turgeon MO, Fish L, Erard N, Gable AL, et al. 2018. Asparagine bioavailability governs metastasis in a model of breast cancer. Nature 554: 378-381. doi:10.1038/nature25465

Koebel CM, Vermi W, Swann JB, Zerafa N, Rodig SJ, Old LJ, Smyth MJ, Schreiber RD. 2007. Adaptive immunity maintains occult cancer in an equilibrium state. Nature 450: 903-907. doi:10.1038/nature06309

Koh B, Jeon H, Kim D, Kang D, Kim KR. 2019. Effect of fibroblast co-culture on the proliferation, viability and drug response of colon cancer cells. Oncol Lett 17: 2409-2417.

Komi DEA, Redegeld FA. 2020. Role of mast cells in shaping the tumor microenvironment. Clin Rev Allergy Immunol 58: 313-325. doi:10.1007/s12016-019-08753-w

Koyama S, Akbay EA, Li YY, Herter-Sprie GS, Buczkowski KA, Richards WG, Gandhi L, Redig AJ, Rodig SJ, Asahina H, et al. 2016. Adaptive resistance to therapeutic PD-1 blockade is associated with upregulation of alternative immune checkpoints. Nat Commun 7: 10501. doi:10.1038/ncomms10501

Krzywinska E, Stockmann C. 2018. Hypoxia, metabolism and immune cell function. Biomedicines 6: 56. doi:10.3390/ biomedicines 6020056

Lamar JM, Stern P, Liu H, Schindler JW, Jiang ZG, Hynes RO. 2012. The Hippo pathway target, YAP, promotes metastasis through its TEAD-interaction domain. Proc Natl Acad Sci 109: E2441-E2450. doi:10.1073/pnas.1212021109

Lambert AW, Pattabiraman DR, Weinberg RA. 2017. Emerging biological principles of metastasis. Cell 168: 670-691. doi:10 .1016/j.cell.2016.11.037 
Lau AN, Curtis SJ, Fillmore CM, Rowbotham SP, Mohseni M, Wagner DE, Beede AM, Montoro DT, Sinkevicius KW, Walton ZE, et al. 2014. Tumor-propagating cells and Yap/Taz activity contribute to lung tumor progression and metastasis. EMBO $J$ 33: 468-481. doi:10.1002/embj.201386082

Le A, Cooper CR, Gouw AM, Dinavahi R, Maitra A, Deck LM, Royer RE, Vander Jagt DL, Semenza GL, Dang CV. 2010. Inhibition of lactate dehydrogenase A induces oxidative stress and inhibits tumor progression. Proc Natl Acad Sci 107: 20372042. doi:10.1073/pnas.0914433107

Lee K, Zhang H, Qian DZ, Rey S, Liu JO, Semenza GL. 2009. Acriflavine inhibits HIF-1 dimerization, tumor growth, and vascularization. Proc Natl Acad Sci 106: 17910-17915. doi:10 .1073/pnas.0909353106

Lee HJ, Diaz MF, Price KM, Ozuna JA, Zhang S, Sevick-Muraca EM, Hagan JP, Wenzel PL. 2017. Fluid shear stress activates YAP1 to promote cancer cell motility. Nat Commun 8: 14122. doi:10.1038/ncomms 14122

Levental KR, Yu H, Kass L, Lakins JN, Egeblad M, Erler JT, Fong SF, Csiszar K, Giaccia A, Weninger W, et al. 2009. Matrix crosslinking forces tumor progression by enhancing integrin signaling. Cell 139: 891-906. doi:10.1016/j.cell.2009.10.027

Li X, Xu Z, Du W, Zhang Z, Wei Y, Wang H, Zhu Z, Qin L, Wang L, Niu Q, et al. 2014. Aiolos promotes anchorage independence by silencing p66Shc transcription in cancer cells. Cancer Cell 25: 575-589. doi:10.1016/j.ccr.2014.03.020

Li L, Ren F, Qi C, Xu L, Fang Y, Liang M, Feng J, Chen B, Ning W, Cao J. 2018. Intermittent hypoxia promotes melanoma lung metastasis via oxidative stress and inflammation responses in a mouse model of obstructive sleep apnea. Respir Res 19: 28. doi:10.1186/s12931-018-0727-x

Liang W, Li Q, Ferrara N. 2018. Metastatic growth instructed by neutrophil-derived transferrin. Proc Natl Acad Sci 115: 11060-11065. doi:10.1073/pnas.1811717115

Liao H, Zhu H, Liu S, Wang H. 2018. Expression of V-domain immunoglobulin suppressor of $\mathrm{T}$ cell activation is associated with the advanced stage and presence of lymph node metastasis in ovarian cancer. Oncol Lett 16: 3465-3472.

Lien SC, Chang SF, Lee PL, Wei SY, Chang MD, Chang JY, Chiu JJ. 2013. Mechanical regulation of cancer cell apoptosis and autophagy: roles of bone morphogenetic protein receptor, Smad1/5, and p38 MAPK. Biochim Biophys Acta 1833: 3124-3133. doi:10.1016/j.bbamcr.2013.08.023

Lin Y, Xu J, Lan H. 2019. Tumor-associated macrophages in tumor metastasis: biological roles and clinical therapeutic applications. I Hematol Oncol 12: 76. doi:10.1186/s13045-0190760-3

Lomelino CL, Andring JT, McKenna R, Kilberg MS. 2017. Asparagine synthetase: function, structure, and role in disease. $I$ Biol Chem 292: 19952-19958. doi:10.1074/jbc.R117.819060

Lopez JI, Kang I, You WK, McDonald DM, Weaver VM. 2011. In situ force mapping of mammary gland transformation. Integr Biol (Camb) 3: 910-921. doi:10.1039/clib00043h

López-Soto A, Gonzalez S, Smyth MJ, Galluzzi L. 2017. Control of metastasis by NK cells. Cancer Cell 32: 135-154. doi:10 .1016/j.ccell.2017.06.009

Lorenzo-Herrero S, López-Soto A, Sordo-Bahamonde C, Gonzalez-Rodriguez AP, Vitale M, Gonzalez S. 2019. NK Cell-Based immunotherapy in cancer metastasis. Cancers (Basel) 11. doi:10.3390/cancers11010029

Lu W, Kang Y. 2019. Epithelial-mesenchymal plasticity in cancer progression and metastasis. Dev Cell 49: 361-374. doi:10 .1016/j.devcel.2019.04.010

Lu CW, Lin SC, Chen KF, Lai YY, Tsai SJ. 2008. Induction of pyruvate dehydrogenase kinase-3 by hypoxia-inducible factor-1 promotes metabolic switch and drug resistance. I Biol Chem 283: 28106-28114. doi:10.1074/jbc.M803508200

Luan Y, Gao C, Miao Y, Li Y, Wang Z, Qiu X. 2013. Clinicopathological and prognostic significance of HIF- $1 \alpha$ and HIF-2 $\alpha$ expression in small cell lung cancer. Pathol Res Pract 209: 184-189. doi:10.1016/j.prp.2012.10.017

Lucero HA, Kagan HM. 2006. Lysyl oxidase: an oxidative enzyme and effector of cell function. Cell Mol Life Sci 63: 2304-2316. doi:10.1007/s00018-006-6149-9

Luo D, Wang J, Li J, Post M. 2011. Mouse snail is a target gene for HIF. Mol Cancer Res 9: 234-245. doi:10.1158/1541-7786 .MCR-10-0214

Macedo F, Ladeira K, Pinho F, Saraiva N, Bonito N, Pinto L, Goncalves F. 2017. Bone metastases: an overview. Oncol Rev 11: 321.

Marijt KA, Sluijter M, Blijleven L, Tolmeijer SH, Scheeren FA, van der Burg SH, van Hall T. 2019. Metabolic stress in cancer cells induces immune escape through a PI3K-dependent blockade of IFN $\gamma$ receptor signaling. I Immunother Cancer 7: 152. doi:10.1186/s40425-019-0627-8

Massagué J, Obenauf AC. 2016. Metastatic colonization by circulating tumour cells. Nature 529: 298-306. doi:10.1038/ nature 17038

McKeown SR. 2014. Defining normoxia, physoxia and hypoxia in tumours-implications for treatment response. Br I Radiol 87: 20130676. doi:10.1259/bjr.20130676

Meng Z, Moroishi T, Guan KL. 2016. Mechanisms of Hippo pathway regulation. Genes Dev 30: 1-17. doi:10.1101/gad.274027 .115

Micalizzi DS, Maheswaran S, Haber DA. 2017. A conduit to metastasis: circulating tumor cell biology. Genes Dev 31: 18271840. doi:10.1101/gad.305805.117

Michelakis ED, Webster L, Mackey JR. 2008. Dichloroacetate (DCA) as a potential metabolic-targeting therapy for cancer. Br J Cancer 99: 989-994. doi:10.1038/sj.bjc.6604554

Miller K, Chinzei K, Orssengo G, Bednarz P. 2000. Mechanical properties of brain tissue in-vivo: experiment and computer simulation. I Biomech 33: 1369-1376. doi:10.1016/S00219290(00)00120-2

Mishra R, Haldar S, Suchanti S, Bhowmick NA. 2019. Epigenetic changes in fibroblasts drive cancer metabolism and differentiation. Endocr Relat Cancer 26: R673-R688. doi:10.1530/ERC19-0347

Mitchell MJ, King MR. 2013. Fluid shear stress sensitizes cancer cells to receptor-mediated apoptosis via trimeric death receptors. New I Phys 15: 015008. doi:10.1088/1367-2630/15/1/ 015008

Mondal M, Guo J, He P, Zhou D. 2020. Recent advances of oncolytic virus in cancer therapy. Hum Vaccin Immunother 1-14. doi:10.1080/21645515.2020.1723363

Mori K, Kimura S, Parizi MK, Enikeev DV, Glybochko PV, Seebacher V, Fajkovic H, Mostafaei H, Lysenko I, Janisch F, et al. 2019. Prognostic value of lactate dehydrogenase in metastatic prostate cancer: a systematic review and meta-analysis. Clin Genitourin Cancer 17: 409-418. doi:10.1016/j.clgc .2019.07.009

Mott JD, Werb Z. 2004. Regulation of matrix biology by matrix metalloproteinases. Curr Opin Cell Biol 16: 558-564. doi:10 $.1016 /$ j.ceb.2004.07.010

Mouw JK, Yui Y, Damiano L, Bainer RO, Lakins JN, Acerbi I, Ou G, Wijekoon AC, Levental KR, Gilbert PM, et al. 2014. Tissue mechanics modulate microRNA-dependent PTEN expression to regulate malignant progression. Nat Med 20: 360-367. doi:10.1038/nm.3497 
Musolino A, Campone M, Neven P, Denduluri N, Barrios CH, Cortes J, Blackwell K, Soliman H, Kahan Z, Bonnefoi H, et al. 2017. Phase II, randomized, placebo-controlled study of dovitinib in combination with fulvestrant in postmenopausal patients with $\mathrm{HR}^{+}, \mathrm{HER} 2^{-}$breast cancer that had progressed during or after prior endocrine therapy. Breast Cancer Res 19: 18. doi:10.1186/s13058-017-0807-8

Muz B, de la Puente P, Azab F, Azab AK. 2015. The role of hypoxia in cancer progression, angiogenesis, metastasis, and resistance to therapy. Hypoxia (Auckl) 3: 83-92. doi:10.2147/HP .S93413

Nolan E, Vaillant F, Branstetter D, Pal B, Giner G, Whitehead L, Lok SW, Mann GB, Rohrbach K, Huang LY, et al. 2016. RANK ligand as a potential target for breast cancer prevention in BRCA1-mutation carriers. Nat Med 22: 933-939. doi:10 $.1038 / \mathrm{nm} .4118$

Noman MZ, Desantis G, Janji B, Hasmim M, Karray S, Dessen P, Bronte V, Chouaib S. 2014. PD-L1 is a novel direct target of HIF-1 $\alpha$, and its blockade under hypoxia enhanced MDSC-mediated T cell activation. J Exp Med 211: 781-790. doi:10.1084/ jem.20131916

Novak CM, Horst EN, Taylor CC, Liu CZ, Mehta G. 2019. Fluid shear stress stimulates breast cancer cells to display invasive and chemoresistant phenotypes while upregulating PLAU in a 3D bioreactor. Biotechnol Bioeng 116: 3084-3097. doi:10 $.1002 /$ bit. 27119

Nunes JB, Everts B. 2019. Metabolic stress triggers immune escape by tumors. Trends Cancer 5: 656-658. doi:10.1016/j .trecan.2019.09.001

Obenauf AC, Massagué J. 2015. Surviving at a distance: organspecific metastasis. Trends Cancer 1: 76-91. doi:10.1016/j .trecan.2015.07.009

O'Reilly MS, Holmgren L, Shing Y, Chen C, Rosenthal RA, Cao Y, Moses M, Lane WS, Sage EH, Folkman J. 1994. Angiostatin: a circulating endothelial cell inhibitor that suppresses angiogenesis and tumor growth. Cold Spring Harb Sym Quant Biol 59: 471-482. doi:10.1101/SQB.1994.059.01.052

Ostermann E, Garin-Chesa P, Heider KH, Kalat M, Lamche H, Puri C, Kerjaschki D, Rettig WJ, Adolf GR. 2008. Effective immunoconjugate therapy in cancer models targeting a serine protease of tumor fibroblasts. Clin Cancer Res 14: 4584-4592. doi:10.1158/1078-0432.CCR-07-5211

Ou J, Peng Y, Deng J, Miao H, Zhou J, Zha L, Zhou R, Yu L, Shi H, Liang H. 2014. Endothelial cell-derived fibronectin extra domain A promotes colorectal cancer metastasis via inducing epithelial-mesenchymal transition. Carcinogenesis 35: 16611670. doi:10.1093/carcin/bgu090

Pàez-Ribes M, Allen E, Hudock J, Takeda T, Okuyama H, Viñals F, Inoue M, Bergers G, Hanahan D, Casanovas O. 2009. Antiangiogenic therapy elicits malignant progression of tumors to increased local invasion and distant metastasis. Cancer Cell 15: 220-231. doi:10.1016/j.ccr.2009.01.027

Pagès F, Berger A, Camus M, Sanchez-Cabo F, Costes A, Molidor R, Mlecnik B, Kirilovsky A, Nilsson M, Damotte D, et al. 2005. Effector memory T cells, early metastasis, and survival in colorectal cancer. $N$ Engl J Med 353: 2654-2666. doi:10 .1056/NEJMoa051424

Paoli P, Giannoni E, Chiarugi P. 2013. Anoikis molecular pathways and its role in cancer progression. Biochim Biophys Acta 1833: 3481-3498. doi:10.1016/j.bbamcr.2013.06.026

Paszek MJ, Zahir N, Johnson KR, Lakins JN, Rozenberg GI, Gefen A, Reinhart-King CA, Margulies SS, Dembo M, Boettiger D, et al. 2005. Tensional homeostasis and the malignant phenotype. Cancer Cell 8: 241-254. doi:10.1016/j.ccr.2005.08.010
Pelizzari G, Basile D, Zago S, Lisanti C, Bartoletti M, Bortot L, Vitale MG, Fanotto V, Barban S, Cinausero M, et al. 2019. Lactate dehydrogenase (LDH) response to first-line treatment predicts survival in metastatic breast cancer: first clues for a costeffective and dynamic biomarker. Cancers (Basel) 11: 1243. doi:10.3390/cancers11091243

Peng W, Chen JQ, Liu C, Malu S, Creasy C, Tetzlaff MT, Xu C, McKenzie JA, Zhang C, Liang X, et al. 2016. Loss of PTEN promotes resistance to $\mathrm{T}$ cell-mediated immunotherapy. Cancer Discov 6: 202-216. doi:10.1158/2159-8290.CD-15-0283

Petrova V, Annicchiarico-Petruzzelli M, Melino G, Amelio I. 2018. The hypoxic tumour microenvironment. Oncogenesis 7: 10. doi:10.1038/s41389-017-0011-9

Pierobon M, Ramos C, Wong S, Hodge KA, Aldrich J, Byron S, Anthony SP, Robert NJ, Northfelt DW, Jahanzeb M, et al. 2017. Enrichment of PI3K-AKT-mTOR pathway activation in hepatic metastases from breast cancer. Clin Cancer Res 23: 4919-4928. doi:10.1158/1078-0432.CCR-16-2656

Poggio M, Hu T, Pai CC, Chu B, Belair CD, Chang A, Montabana E, Lang UE, Fu Q, Fong L, et al. 2019. Suppression of exosomal PD-L1 induces systemic anti-tumor immunity and memory. Cell 177: 414-427.e13. doi:10.1016/j.cell.2019.02.016

Priego N, Zhu L, Monteiro C, Mulders M, Wasilewski D, Bindeman W, Doglio L, Martínez L, Martínez-Saez E, Ramón YCS, et al. 2018. STAT3 labels a subpopulation of reactive astrocytes required for brain metastasis. Nat Med 24: 10241035. doi:10.1038/s41591-018-0044-4

Qian BZ, Pollard JW. 2010. Macrophage diversity enhances tumor progression and metastasis. Cell 141:39-51. doi:10.1016/j.cell .2010.03.014

Qin S, Xu L, Yi M, Yu S, Wu K, Luo S. 2019. Novel immune checkpoint targets: moving beyond PD-1 and CTLA-4. Mol Cancer 18: 155. doi:10.1186/s12943-019-1091-2

Raab-Westphal S, Marshall JF, Goodman SL. 2017. Integrins as therapeutic targets: successes and cancers. Cancers (Basel) 9: 110. doi:10.3390/cancers9090110

Rankin EB, Nam JM, Giaccia AJ. 2016. Hypoxia: signaling the metastatic cascade. Trends Cancer 2: 295-304. doi:10.1016/j .trecan.2016.05.006

Rhim AD, Mirek ET, Aiello NM, Maitra A, Bailey JM, McAllister F, Reichert M, Beatty GL, Rustgi AK, Vonderheide RH, et al. 2012. EMT and dissemination precede pancreatic tumor formation. Cell 148: 349-361. doi:10.1016/j.cell.2011.11.025

Ritter C, Fan K, Paschen A, Reker Hardrup S, Ferrone S, Nghiem P, Ugurel S, Schrama D, Becker JC. 2017. Epigenetic priming restores the HLA class-I antigen processing machinery expression in merkel cell carcinoma. Sci Rep 7: 2290. doi:10.1038/ s41598-017-02608-0

Ruppender NS, Merkel AR, Martin TJ, Mundy GR, Sterling JA, Guelcher SA. 2010. Matrix rigidity induces osteolytic gene expression of metastatic breast cancer cells. PLoS One 5: e15451. doi:10.1371/journal.pone.0015451

Saatci O, Kaymak A, Raza U, Ersan PG, Akbulut O, Banister CE, Sikirzhytski V, Tokat UM, Aykut G, Ansari SA, et al. 2020. Targeting lysyl oxidase (LOX) overcomes chemotherapy resistance in triple negative breast cancer. Nat Commun 11: 2416. doi:10.1038/s41467-020-16199-4

Sakamoto S, McCann RO, Dhir R, Kyprianou N. 2010. Talin1 promotes tumor invasion and metastasis via focal adhesion signaling and anoikis resistance. Cancer Res 70: 1885-1895. doi:10.1158/0008-5472.CAN-09-2833

Salvador F, Martin A, López-Menéndez C, Moreno-Bueno G, Santos V, Vázquez-Naharro A, Santamaria PG, Morales S, Dubus PR, Muinelo-Romay L, et al. 2017. Lysyl oxidase-like protein 
LOXL2 promotes lung metastasis of breast cancer. Cancer Res 77: 5846-5859. doi:10.1158/0008-5472.CAN-16-3152

Saraei P, Asadi I, Kakar MA, Moradi-Kor N. 2019. The beneficial effects of metformin on cancer prevention and therapy: a comprehensive review of recent advances. Cancer Manag Res 11: 3295-3313. doi:10.2147/CMAR.S200059

Schaefer L, Schaefer RM. 2010. Proteoglycans: from structural compounds to signaling molecules. Cell Tissue Res 339: 237-246. doi:10.1007/s00441-009-0821-y

Schaefer KL, Wada K, Takahashi H, Matsuhashi N, Ohnishi S, Wolfe MM, Turner JR, Nakajima A, Borkan SC, Saubermann LJ. 2005. Peroxisome proliferator-activated receptor $\gamma$ inhibition prevents adhesion to the extracellular matrix and induces anoikis in hepatocellular carcinoma cells. Cancer Res 65: 2251-2259. doi:10.1158/0008-5472.CAN-04-3037

Seewaldt V. 2014. ECM stiffness paves the way for tumor cells. Nat Med 20: 332-333. doi:10.1038/nm.3523

Seidel JA, Otsuka A, Kabashima K. 2018. Anti-PD-1 and anti-CTLA-4 therapies in cancer: mechanisms of action, efficacy, and limitations. Front Oncol 8: 86. doi:10.3389/fonc .2018 .00086

Semenza GL. 2012. Hypoxia-inducible factors in physiology and medicine. Cell 148: 399-408. doi:10.1016/j.cell.2012.01.021

Semenza GL. 2014. Oxygen sensing, hypoxia-inducible factors, disease pathophysiology. Annu Rev Pathol 9: 47-71. doi:10 .1146/annurev-pathol-012513-104720

Sethi N, Kang Y. 2011. Notch signalling in cancer progression and bone metastasis. Br J Cancer 105: 1805-1810. doi:10.1038/bjc .2011 .497

Sethi N, Dai X, Winter CG, Kang Y. 2011. Tumor-derived JAGGED1 promotes osteolytic bone metastasis of breast cancer by engaging notch signaling in bone cells. Cancer Cell 19: 192-205. doi:10.1016/j.ccr.2010.12.022

Seyfried TN, Huysentruyt LC. 2013. On the origin of cancer metastasis. Crit Rev Oncog 18: 43-73. doi:10.1615/CritRevOn cog.v18.i1-2.40

Shang S, Ji X, Zhang L, Chen J, Li C, Shi R, Xiang W, Kang X, Zhang D, Yang F, et al. 2019. Macrophage ABHD5 suppresses NFKB-dependent matrix metalloproteinase expression and cancer metastasis. Cancer Res 79: 5513-5526. doi:10.1158/ 0008-5472.CAN-19-1059

Shen M, Jiang YZ, Wei Y, Ell B, Sheng X, Esposito M, Kang J, Hang $\mathrm{X}$, Zheng H, Rowicki M, et al. 2019. Tinagll suppresses triplenegative breast cancer progression and metastasis by simultaneously inhibiting integrin/FAK and EGFR signaling. Cancer Cell 35: 64-80.e7. doi:10.1016/j.ccell.2018.11.016

Shibue T, Weinberg RA. 2009. Integrin $\beta 1$-focal adhesion kinase signaling directs the proliferation of metastatic cancer cells disseminated in the lungs. Proc Natl Acad Sci 106: 1029010295. doi:10.1073/pnas.0904227106

Shiozawa Y, Pedersen EA, Havens AM, Jung Y, Mishra A, Joseph J, Kim JK, Patel LR, Ying C, Ziegler AM, et al. 2011. Human prostate cancer metastases target the hematopoietic stem cell niche to establish footholds in mouse bone marrow. I Clin Invest 121: 1298-1312. doi:10.1172/JCI43414

Sigl V, Jones LP, Penninger JM. 2016. RANKL/RANK: from bone loss to the prevention of breast cancer. Open Biol 6: 160230 . doi:10.1098/rsob.160230

Simpson CD, Anyiwe K, Schimmer AD. 2008. Anoikis resistance and tumor metastasis. Cancer Lett 272: 177-185. doi:10.1016/ j.canlet.2008.05.029

Skobe M, Hawighorst T, Jackson DG, Prevo R, Janes L, Velasco P, Riccardi L, Alitalo K, Claffey K, Detmar M. 2001. Induction of tumor lymphangiogenesis by VEGF-C promotes breast cancer metastasis. Nat Med 7: 192-198. doi:10.1038/84643
Slaney CY, Kershaw MH, Darcy PK. 2014. Trafficking of T cells into tumors. Cancer Res 74: 7168-7174. doi:10.1158/00085472.CAN-14-2458

Smith HA, Kang YB. 2017. Determinants of organotropic metastasis. Annu Rev Canc Biol 1: 403-423. doi:10.1146/annurevcancerbio-041916-064715

Soria JC, Lee HY, Lee JI, Wang L, Issa JP, Kemp BL, Liu DD, Kurie JM, Mao L, Khuri FR. 2002. Lack of PTEN expression in nonsmall cell lung cancer could be related to promoter methylation. Clin Cancer Res 8: 1178-1184.

Sosa MS, Bragado P, Aguirre-Ghiso JA. 2014. Mechanisms of disseminated cancer cell dormancy: an awakening field. Nat Rev Cancer 14: 611-622. doi:10.1038/nrc3793

Spranger S, Bao R, Gajewski TF. 2015. Melanoma-intrinsic $\beta$-catenin signalling prevents anti-tumour immunity. Nature 523: 231-235. doi:10.1038/nature14404

Stacker SA, Caesar C, Baldwin ME, Thornton GE, Williams RA, Prevo R, Jackson DG, Nishikawa S, Kubo H, Achen MG. 2001. VEGF-D promotes the metastatic spread of tumor cells via the lymphatics. Nat Med 7: 186-191. doi:10.1038/84635

Stein M, Lin H, Jeyamohan C, Dvorzhinski D, Gounder M, Bray K, Eddy S, Goodin S, White E, Dipaola RS. 2010. Targeting tumor metabolism with 2-deoxyglucose in patients with castrate-resistant prostate cancer and advanced malignancies. Prostate 70: 1388-1394. doi:10.1002/pros.21172

Strowitzki MJ, Cummins EP, Taylor CT. 2019. Protein hydroxylation by hypoxia-inducible factor (HIF) hydroxylases: unique or ubiquitous? Cells 8: 384. doi:10.3390/cells8050384

Su W, Han HH, Wang Y, Zhang B, Zhou B, Cheng Y, Rumandla A, Gurrapu S, Chakraborty G, Su J, et al. 2019. The polycomb repressor complex 1 drives double-negative prostate cancer metastasis by coordinating stemness and immune suppression. Cancer Cell 36: 139-155.e10. doi:10.1016/j.ccell.2019.06.009

Sun C, Xu J, Huang Q, Huang M, Wen H, Zhang C, Wang J, Song J, Zheng M, Sun H, et al. 2017. High NKG2A expression contributes to NK cell exhaustion and predicts a poor prognosis of patients with liver cancer. Oncoimmunology 6: e1264562. doi:10.1080/2162402X.2016.1264562

Sundahl N, Duprez F, Ost P, De Neve W, Mareel M. 2018. Effects of radiation on the metastatic process. Mol Med 24: 16. doi:10 .1186/s10020-018-0015-8

Swaminathan V, Mythreye K, O'Brien ET, Berchuck A, Blobe GC, Superfine R. 2011. Mechanical stiffness grades metastatic potential in patient tumor cells and in cancer cell lines. Cancer Res 71: 5075-5080. doi:10.1158/0008-5472.CAN-11-0247

Takamiya R, Ohtsubo K, Takamatsu S, Taniguchi N, Angata T. 2013. The interaction between siglec-15 and tumor-associated sialyl-Tn antigen enhances TGF- $\beta$ secretion from monocytes/ macrophages through the DAP12-Syk pathway. Glycobiology 23: 178-187. doi:10.1093/glycob/cws139

Tamura R, Tanaka T, Akasaki Y, Murayama Y, Yoshida K, Sasaki H. 2020. The role of vascular endothelial growth factor in the hypoxic and immunosuppressive tumor microenvironment: perspectives for therapeutic implications. Med Oncol 37: 2. doi:10.1007/s12032-019-1329-2

Tavare AN, Perry NJ, Benzonana LL, Takata M, Ma D. 2012. Cancer recurrence after surgery: direct and indirect effects of anesthetic agents. Int I Cancer 130: 1237-1250. doi:10.1002/ijc .26448

Tolaney SM, Barry WT, Dang CT, Yardley DA, Moy B, Marcom PK, Albain KS, Rugo HS, Ellis M, Shapira I, et al. 2015. Adjuvant paclitaxel and trastuzumab for node-negative, HER2-positive breast cancer. N Engl J Med 372: 134-141. doi:10.1056/ NEJMoa1406281 
Tomida C, Yamagishi N, Nagano H, Uchida T, Ohno A, Hirasaka K, Nikawa T, Teshima-Kondo S. 2018. VEGF pathway-targeting drugs induce evasive adaptation by activation of neuropilin-1/cMet in colon cancer cells. Int J Oncol 52: 1350-1362.

Trojan J, Brieger A, Raedle J, Esteller M, Zeuzem S. 2000. 5'-CpG island methylation of the LKB1/STK11 promoter and allelic loss at chromosome $19 \mathrm{p} 13.3$ in sporadic colorectal cancer. Gut 47: 272-276. doi:10.1136/gut.47.2.272

Ugurel S, Spassova I, Wohlfarth J, Drusio C, Cherouny A, Melior A, Sucker A, Zimmer L, Ritter C, Schadendorf D, et al. 2019. MHC class-I downregulation in PD-1/PD-L1 inhibitor refractory merkel cell carcinoma and its potential reversal by histone deacetylase inhibition: a case series. Cancer Immunol Immunother 68: 983-990. doi:10.1007/s00262-019-02341-9

Valastyan S, Weinberg RA. 2011. Tumor metastasis: molecular insights and evolving paradigms. Cell 147: 275-292. doi:10 $.1016 /$ j.cell.2011.09.024

Valiente M, Obenauf AC, Jin X, Chen Q, Zhang XH, Lee DJ, Chaft JE, Kris MG, Huse JT, Brogi E, et al. 2014. Serpins promote cancer cell survival and vascular co-option in brain metastasis. Cell 156: 1002-1016. doi:10.1016/j.cell.2014.01.040

Van den Eynden GG, Majeed AW, Illemann M, Vermeulen PB, Bird NC, Hoyer-Hansen G, Eefsen RL, Reynolds AR, Brodt P. 2013. The multifaceted role of the microenvironment in liver metastasis: biology and clinical implications. Cancer Res 73: 2031-2043. doi:10.1158/0008-5472.CAN-12-3931

Vanharanta S, Shu W, Brenet F, Hakimi AA, Heguy A, Viale A, Reuter VE, Hsieh JJ, Scandura JM, Massagué J. 2013. Epigenetic expansion of VHL-HIF signal output drives multiorgan metastasis in renal cancer. Nat Med 19: 50-56. doi:10.1038/nm .3029

van 't Veer LJ, Dai H, van de Vijver MJ, He YD, Hart AA, Mao M, Peterse HL, van der Kooy K, Marton MJ, Witteveen AT, et al. 2002. Gene expression profiling predicts clinical outcome of breast cancer. Nature 415: 530-536. doi:10.1038/415530a

Vogelstein B, Papadopoulos N, Velculescu VE, Zhou S, Diaz LA Jr., Kinzler KW. 2013. Cancer genome landscapes. Science 339: 1546-1558. doi:10.1126/science. 1235122

von Ahrens D, Bhagat TD, Nagrath D, Maitra A, Verma A. 2017. The role of stromal cancer-associated fibroblasts in pancreatic cancer. I Hematol Oncol 10: 76. doi:10.1186/s13045-0170448-5

Vredevoogd DW, Kuilman T, Ligtenberg MA, Boshuizen J, Stecker KE, de Bruijn B, Krijgsman O, Huang X, Kenski JCN, Lacroix R, et al. 2020. Augmenting immunotherapy impact by lowering tumor TNF cytotoxicity threshold. Cell 180: 404-405. doi:10.1016/j.cell.2020.01.005

Walker C, Mojares E, Del Rio Hernandez A. 2018. Role of extracellular matrix in development and cancer progression. Int $I$ Mol Sci 19: 3028. doi:10.3390/ijms19103028

Wang H, Yu C, Gao X, Welte T, Muscarella AM, Tian L, Zhao H, Zhao Z, Du S, Tao J, et al. 2015. The osteogenic niche promotes early-stage bone colonization of disseminated breast cancer cells. Cancer Cell 27: 193-210. doi:10.1016/j.ccell .2014.11.017

Wang J, Kaplan JA, Colson YL, Grinstaff MW. 2017. Mechanoresponsive materials for drug delivery: harnessing forces for controlled release. Adv Drug Deliv Rev 108: 68-82. doi:10.1016/j .addr.2016.11.001

Wang X, Zhang Y, Feng T, Su G, He J, Gao W, Shen Y, Liu X. 2018. Fluid shear stress promotes autophagy in hepatocellular carcinoma cells. Int J Biol Sci 14: 1277-1290. doi:10.7150/ijbs .27055

Wang J, Sun J, Liu LN, Flies DB, Nie X, Toki M, Zhang J, Song C, Zarr M, Zhou X, et al. 2019a. Siglec-15 as an immune suppres- sor and potential target for normalization cancer immunotherapy. Nat Med 25: 656-666. doi:10.1038/s41591-0190374-x

Wang JB, Huang X, Li FR. 2019b. Impaired dendritic cell functions in lung cancer: a review of recent advances and future perspectives. Cancer Commun (Lond) 39: 43. doi:10.1186/s40880019-0387-3

Wang X, Liu R, Zhu W, Chu H, Yu H, Wei P, Wu X, Zhu H, Gao H, Liang J, et al. 2019c. UDP-glucose accelerates SNAI1 mRNA decay and impairs lung cancer metastasis. Nature 571: $127-$ 131. doi:10.1038/s41586-019-1340-y

Wculek SK, Malanchi I. 2015. Neutrophils support lung colonization of metastasis-initiating breast cancer cells. Nature 528: 413-417. doi:10.1038/nature16140

Wei SC, Fattet L, Tsai JH, Guo Y, Pai VH, Majeski HE, Chen AC, Sah RL, Taylor SS, Engler AJ, et al. 2015. Matrix stiffness drives epithelial-mesenchymal transition and tumour metastasis through a TWIST1-G3BP2 mechanotransduction pathway. Nat Cell Biol 17: 678-688. doi:10.1038/ncb3157

Wei J, Long L, Zheng W, Dhungana Y, Lim SA, Guy C, Wang Y, Wang YD, Qian C, Xu B, et al. 2019. Targeting REGNASE-1 programs long-lived effector $\mathrm{T}$ cells for cancer therapy. Nature 576: 471-476. doi:10.1038/s41586-019-1821-z

Weigel KJ, Jakimenko A, Conti BA, Chapman SE, Kaliney WJ, Leevy WM, Champion MM, Schafer ZT. 2014. CAF-secreted IGFBPs regulate breast cancer cell anoikis. Mol Cancer Res 12: 855-866. doi:10.1158/1541-7786.MCR-14-0090

Wessels DJ, Pradhan N, Park YN, Klepitsch MA, Lusche DF, Daniels KJ, Conway KD, Voss ER, Hegde SV, Conway TP, et al. 2019. Reciprocal signaling and direct physical interactions between fibroblasts and breast cancer cells in a $3 \mathrm{D}$ environment. PLoS One 14: e0218854. doi:10.1371/journal.pone.0218854

Wherry EJ. 2011. T cell exhaustion. Nat Immunol 12: 492-499. doi:10.1038/ni.2035

Winer A, Adams S, Mignatti P. 2018. Matrix metalloproteinase inhibitors in cancer therapy: Turning past failures into future successes. Mol Cancer Ther 17: 1147-1155. doi:10.1158/15357163.MCT-17-0646

Wirtz D, Konstantopoulos K, Searson PC. 2011. The physics of cancer: the role of physical interactions and mechanical forces in metastasis. Nat Rev Cancer 11: 512-522. doi:10.1038/ nrc3080

Wozniak MA, Desai R, Solski PA, Der CJ, Keely PJ. 2003. ROCKgenerated contractility regulates breast epithelial cell differentiation in response to the physical properties of a three-dimensional collagen matrix. I Cell Biol 163: 583-595. doi:10 $.1083 /$ jcb. 200305010

Xie J, Xia L, Xiang W, He W, Yin H, Wang F, Gao T, Qi W, Yang Z, Yang X, et al. 2020. Metformin selectively inhibits metastatic colorectal cancer with the KRAS mutation by intracellular accumulation through silencing MATE1. Proc Natl Acad Sci 117: 13012-13022. doi:10.1073/pnas.1918845117

Xiu MX, Liu YM, Kuang BH. 2020. The oncogenic role of Jagged1/ notch signaling in cancer. Biomed Pharmacother 129: 110416. doi:10.1016/j.biopha.2020.110416.

Yamaguchi K, Takagi Y, Aoki S, Futamura M, Saji S. 2000. Significant detection of circulating cancer cells in the blood by reverse transcriptase-polymerase chain reaction during colorectal cancer resection. Ann Surg 232: 58-65. doi:10 .1097/00000658-200007000-00009

Yang MH, Wu MZ, Chiou SH, Chen PM, Chang SY, Liu CJ, Teng SC, Wu KJ. 2008. Direct regulation of TWIST by HIF-1 $\alpha$ promotes metastasis. Nat Cell Biol 10: 295-305. doi:10.1038/ ncb1691 
Yu L, Hales CA. 2011. Long-term exposure to hypoxia inhibits tumor progression of lung cancer in rats and mice. BMC Cancer 11: 331. doi:10.1186/1471-2407-11-331

Yuno A, Lee MJ, Lee S, Tomita Y, Rekhtman D, Moore B, Trepel JB. 2018. Clinical evaluation and biomarker profiling of Hsp90 inhibitors. Methods Mol Biol 1709: 423-441. doi:10.1007/9781-4939-7477-1_29

Zaytseva YY, Wallis NK, Southard RC, Kilgore MW. 2011. The PPAR $\gamma$ antagonist T0070907 suppresses breast cancer cell proliferation and motility via both PPAR $\gamma$-dependent and -independent mechanisms. Anticancer Res 31: 813-823.

Zhang J, Wang L. 2019. The emerging world of TCR-T cell trials against cancer: a systematic review. Technol Cancer Res Treat 18: 1533033819831068.

Zhang L, Conejo-Garcia JR, Katsaros D, Gimotty PA, Massobrio M, Regnani G, Makrigiannakis A, Gray H, Schlienger K, Liebman $\mathrm{MN}$, et al. 2003. Intratumoral $\mathrm{T}$ cells, recurrence, and survival in epithelial ovarian cancer. N Engl J Med 348: 203213. doi:10.1056/NEJMoa020177

Zhang W, Shi X, Peng Y, Wu M, Zhang P, Xie R, Wu Y, Yan Q, Liu S, Wang J. 2015. HIF-1a Promotes epithelial-mesenchymal transition and metastasis through direct regulation of ZEB1 in colorectal cancer. PLoS One 10: e0129603. doi:10.1371/jour nal.pone.0129603

Zheng H, Bae Y, Kasimir-Bauer S, Tang R, Chen J, Ren G, Yuan M, Esposito M, Li W, Wei Y, et al. 2017. Therapeutic antibody targeting tumor- and osteoblastic niche-derived Jagged 1 sensitizes bone metastasis to chemotherapy. Cancer Cell 32: 731747.e6. doi:10.1016/j.ccell.2017.11.002

Zhou SL, Dai Z, Zhou ZJ, Wang XY, Yang GH, Wang Z, Huang XW, Fan J, Zhou J. 2012. Overexpression of CXCL5 mediates neutrophil infiltration and indicates poor prognosis for hepatocellular carcinoma. Hepatology 56: 2242-2254. doi:10 .1002/hep. 25907

Zhou SL, Dai Z, Zhou ZJ, Chen Q, Wang Z, Xiao YS, Hu ZQ, Huang XY, Yang GH, Shi YH, et al. 2014a. CXCL5 contributes to tumor metastasis and recurrence of intrahepatic cholangiocarcinoma by recruiting infiltrative intratumoral neutrophils. Carcinogenesis 35: 597-605. doi:10.1093/carcin/bgt397

Zhou W, Fong MY, Min Y, Somlo G, Liu L, Palomares MR, Yu Y, Chow A, O'Connor ST, Chin AR, et al. 2014b. Cancer-secreted miR-105 destroys vascular endothelial barriers to promote metastasis. Cancer Cell 25: 501-515. doi:10.1016/j.ccr.2014 .03 .007

Zhou Q, Wu X, Wang X, Yu Z, Pan T, Li Z, Chang X, Jin Z, Li J, $Z$ hu $Z$, et al. 2020. The reciprocal interaction between tumor cells and activated fibroblasts mediated by TNF- $\alpha /$ IL-33/ST2L signaling promotes gastric cancer metastasis. Oncogene 39: 1414-1428. doi:10.1038/s41388-019-1078-x

Zhu P, Tan MJ, Huang RL, Tan CK, Chong HC, Pal M, Lam CR, Boukamp P, Pan JY, Tan SH, et al. 2011. Angiopoietin-like 4 protein elevates the prosurvival intracellular $\mathrm{O} 2^{-}: \mathrm{H} 2 \mathrm{O} 2$ ratio and confers anoikis resistance to tumors. Cancer Cell 19:401415. doi:10.1016/j.ccr.2011.01.018

Zhu HD, Liu L, Deng H, Li ZB, Sheng JQ, He XX, Tian DA, Li PY. 2020. Astrocyte elevated gene 1 (AEG-1) promotes anoikis resistance and metastasis by inducing autophagy in hepatocellular carcinoma. J Cell Physiol 235: 5084-5095. doi:10.1002/ jcp. 29377

Zou W, Wolchok JD, Chen L. 2016. PD-L1 (B7-H1) and PD-1 pathway blockade for cancer therapy: mechanisms, response biomarkers, and combinations. Sci Transl Med 8: 328rv324.

Zuo H, Yang D, Yang Q, Tang H, Fu YX, Wan Y. 2020. Differential regulation of breast cancer bone metastasis by PARP1 and PARP2. Nat Commun 11: 1578. doi:10.1038/s41467-02015429-z

Zysset PK, Guo XE, Hoffler CE, Moore KE, Goldstein SA. 1999. Elastic modulus and hardness of cortical and trabecular bone lamellae measured by nanoindentation in the human femur. J Biomech 32: 1005-1012. doi:10.1016/S0021-9290(99) 00111-6 


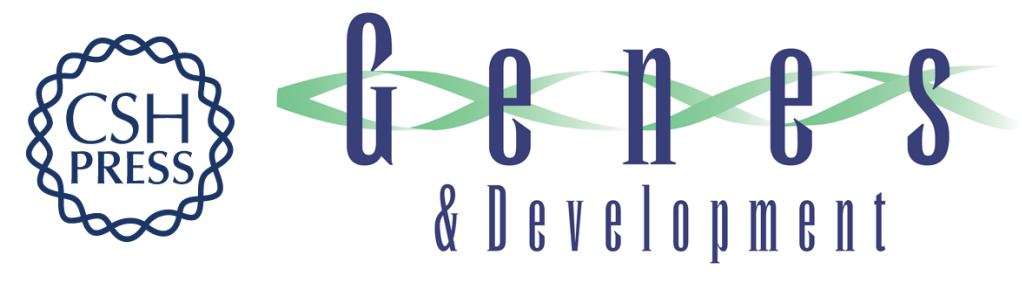

\section{Stresses in the metastatic cascade: molecular mechanisms and therapeutic opportunities}

Minhong Shen and Yibin Kang

Genes Dev. 2020, 34:

Access the most recent version at doi:10.1101/gad.343251.120

References

Creative

Commons

License

Email Alerting
Service
This article cites 242 articles, 53 of which can be accessed free at: http://genesdev.cshlp.org/content/34/23-24/1577.full.html\#ref-list-1

This article is distributed exclusively by Cold Spring Harbor Laboratory Press for the first six months after the full-issue publication date (see

http://genesdev.cshlp.org/site/misc/terms.xhtml). After six months, it is available under a Creative Commons License (Attribution-NonCommercial 4.0 International), as described at http://creativecommons.org/licenses/by-nc/4.0/.

Receive free email alerts when new articles cite this article - sign up in the box at the top right corner of the article or click here.

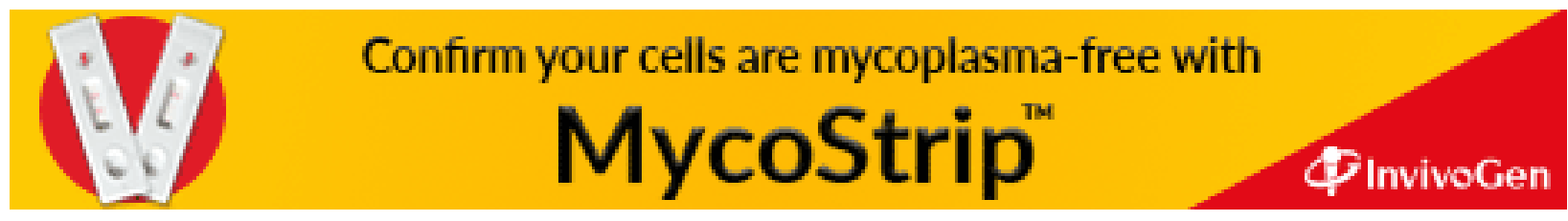

